OPEN ACCESS

Edited by:

Rosita Angela Condorelli, University of Catania, Italy

Reviewed by:

Rima Dada,

All India Institute of Medical

Sciences, India

Giulia Rastrelli,

University of Florence, Italy

${ }^{*}$ Correspondence:

Robert John Aitken john.aitken@newcastle.edu.au

Specialty section: This article was submitted to Reproduction,

a section of the journal

Frontiers in Endocrinology

Received: 17 July 2020 Accepted: 07 September 2020

Published: 30 September 2020

Citation:

Aitken RJ and Baker MA (2020) The Role of Genetics and Oxidative Stress in the Etiology of Male Infertility $-A$ Unifying Hypothesis?

Front. Endocrinol. 11:581838 doi: $10.3389 /$ fendo.2020.581838

\section{The Role of Genetics and Oxidative Stress in the Etiology of Male Infertility-A Unifying Hypothesis?}

\author{
Robert John Aitken ${ }^{1,2 *}$ and Mark A. Baker ${ }^{1,2}$ \\ ${ }^{1}$ Faculty of Science and Faculty of Health and Medicine, Priority Research Centre in Reproductive Science, University of \\ Newcastle, Callaghan, NSW, Australia, ${ }^{2}$ Hunter Medical Research Institute, New Lambton Heights, NSW, Australia
}

Despite the high prevalence of male infertility, very little is known about its etiology. In recent years however, advances in gene sequencing technology have enabled us to identify a large number of rare single point mutations responsible for impeding all aspects of male reproduction from its embryonic origins, through the endocrine regulation of spermatogenesis to germ cell differentiation and sperm function. Such monogenic mutations aside, the most common genetic causes of male infertility are aneuploidies such as Klinefelter syndrome and Y-chromosome mutations which together account for around $20-25 \%$ of all cases of non-obstructive azoospermia. Oxidative stress has also emerged as a major cause of male fertility with at least $40 \%$ of patients exhibiting some evidence of redox attack, resulting in high levels of lipid peroxidation and oxidative DNA damage in the form of 8-hydroxy-2'-deoxyguanosine (8OHdG). The latter is highly mutagenic and may contribute to de novo mutations in our species, $75 \%$ of which are known to occur in the male germ line. An examination of $80 \mathrm{HdG}$ lesions in the human sperm genome has revealed $\sim 9,000$ genomic regions vulnerable to oxidative attack in spermatozoa. While these oxidized bases are generally spread widely across the genome, a particular region on chromosome 15 appears to be a hot spot for oxidative attack. This locus maps to a genetic location which has linkages to male infertility, cancer, imprinting disorders and a variety of behavioral conditions (autism, bipolar disease, spontaneous schizophrenia) which have been linked to the age of the father at the moment of conception. We present a hypothesis whereby a number of environmental, lifestyle and clinical factors conspire to induce oxidative DNA damage in the male germ line which then triggers the formation de novo mutations which can have a major impact on the health of the offspring including their subsequent fertility.

Keywords: male infertility, mutation, oxidative stress, spermatozoa, DNA damage

\section{INTRODUCTION}

Spermatogenesis is an immensely complicated process involving the coordinated action of thousands of genes in order to generate one of the most complex, specialized cell types in human biology, the spermatozoon. Given this complexity, it may not be surprising that "the male factor" is held to be a major contributor to human infertility, although, the extent of this contribution is still a matter for conjecture. A recent survey of papers that have set out to determine the 
causes of human infertility by assigning each case to one of four categories (male factor, female factor, both male and female factors, and unexplained) indicated that defects in the male were, on average $( \pm S E M)$, thought to account for $21.1 \pm$ $2.8 \%$ of all infertility, while the remaining causes distributed as follows: female factors $(42.8 \pm 3.2 \%)$, combined male and female factors $(24.2 \pm 4.9 \%)$ and unexplained infertility $(13.2 \pm$ $2.1 \%$ ) (1). Examination of individual studies reveals a wide range of estimates for the incidence of male infertility (5-35\%) that may reflect real differences between populations in terms of the quality of primary health care, occupational and environmental exposures to reproductive toxicants, age, dietary factors, obesity, climate, education, recreational exposure to drugs and genetic as well as epigenetic factors (1).

The major problem with all of these assessments is that the existence of male factor infertility was determined on the basis of a conventional semen profile. While the latter is acknowledged as a fundamental component of diagnostic andrology, with few exceptions, it is also widely understood that the criteria used to create such semen profiles (sperm count, motility and morphology) are not precisely predictive of infertility. In a prospective study of patients exhibiting unexplained infertility (normal female partner and normal conventional semen profile), these criteria were found be incapable of predicting the chances of spontaneous conception during a follow-up period lasting up to 4 years during which the patients received no further treatment (2). Similarly, in assisted conception cycles, including both in vitro fertilization (IVF) and intracytoplasmic sperm injection (ICSI) the conventional semen profile has been found to be of no value in predicting fertilization rates (3). However, when elements of the semen profile are combined with other data describing, for example, competence for sperm-oocyte fusion, the detailed movement characteristics of the spermatozoa and aspects of oxidative stress, then algorithms can be generated that better predict the relative fertility of males in vitro and in vivo $(2,4,5)$. The exception to this rule is when the semen profile is seriously flawed, as is the case with azoospermia or severe oligozoospermia $(<5 \mathrm{million} / \mathrm{ml})$ where fertility rates are significantly reduced as might be anticipated (6). At the same time, it should be recognized normal fertility is possible in men whose sperm counts have been suppressed well into the oligospermic range $(<5$ million per $\mathrm{ml}$ ) as a result of exogenous steroid administration (7).

We can conclude from such studies that the traditional approach to male infertility diagnosis, which relies on comparing each element of the semen profile with thresholds of normality established by the World Health Organization, is seriously flawed, no matter how carefully those thresholds were established (8). For the most part, male fertility is not a question of possessing more than a certain critical number of motile, morphologically normal spermatozoa in the ejaculate. It is not a binary phenomenon that allows us to classify patients as "fertile" or "infertile" groups. With the exception of patients exhibiting azoospermia or certain genetic defects such as Kartagener syndrome, most males are on a continuum of relative fertility. Where any given patient lies on this continuum cannot be reliably ascertained by conventional semenology. The diagnostic value of the conventional semen profile lies only in its ability to reflect the quality of the underlying spermatogenic process. Although there may be general low-level statistical correlations between morphology or total sperm number and fertility, the ranges for each of these criteria are so broad that their prognostic significance is very limited (9)-and they tell us nothing about etiology (Figure 1A). Terms such as asthenozoospermia, oligozoospermia, and teratozoospermia are convenient, descriptive terms. However, they are not diagnoses in the true sense of the word. As a consequence, we have greatly overestimated our understanding of the causes of human infertility and, in reality, have very limited insight into the overall contribution made by the "male factor." Much of male infertility is, in fact, idiopathic.

Fortunately, this bleak landscape is gradually changing as we acquire more knowledge of the mechanisms regulating sperm production and function. For example, the impact of genetics and epigenetics on male fertility has been revealed in recent years, largely as a consequence of technical advances in our ability to screen the genome for differences in DNA methylation profile and single nucleotide polymorphisms/mutations. Similarly, many studies describe oxidative stress as another significant cause of male infertility that influences the functionality of spermatozoa and the integrity of their DNA. In this review, we shall consider the progress that has been made in establishing the relative contributions of genetics and oxidative stress to the etiology of previously unexplained male infertility. We shall also tentatively present a unifying hypothesis suggesting that these two contributors to the pathophysiology of male reproduction may well be causally linked.

\section{GENETIC CAUSES OF MALE INFERTILITY \\ Mutations Affecting Sperm Structure and Function}

Mutations and epimutations in the male germ line can affect the functional competence of spermatozoa and/or their primary production. Examples of mutations that influence sperm quality include conditions that affect the morphological appearance of spermatozoa and their competence for fertilization. A classic example of such a condition is globozoospermia. Patients exhibiting globozoospermia produce spermatozoa with spherical-shaped heads, no acrosome and a disorganized midpiece characterized by excess amounts of residual cytoplasm (Figure 1B). Interestingly, globozoospermic spermatozoa possess normal flagella that are capable of progressive motility and, under the appropriate conditions, can exhibit hyperactivation. However, these cells are incapable of binding to the zona pellucida and achieving sperm-oocyte fusion, even after treatment with the calcium ionophore, A23187 (10). These functional defects can be circumvented through the application of ICSI, although, even with this technique, fertilization rates are low. One of the reasons for the lack of fertilization is that globozoospermic spermatozoa are deficient in phospholipase

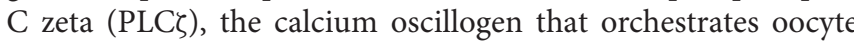
activation at fertilization. Artificial oocyte activation in concert 
A

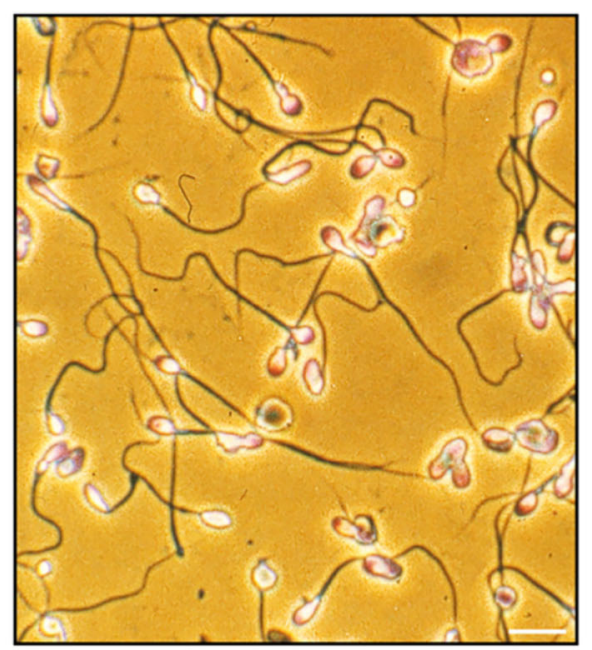

c
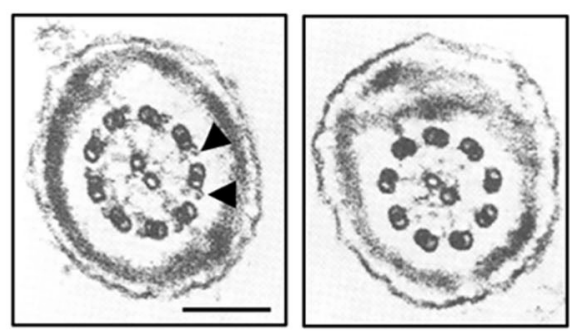

E
B

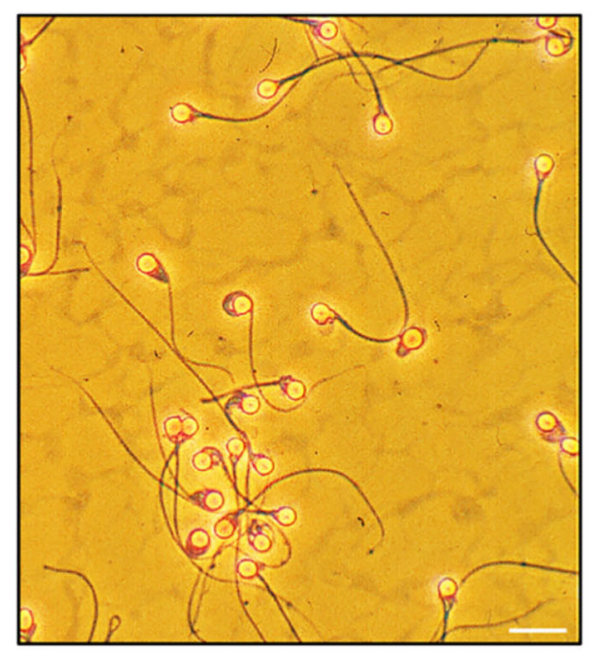

D
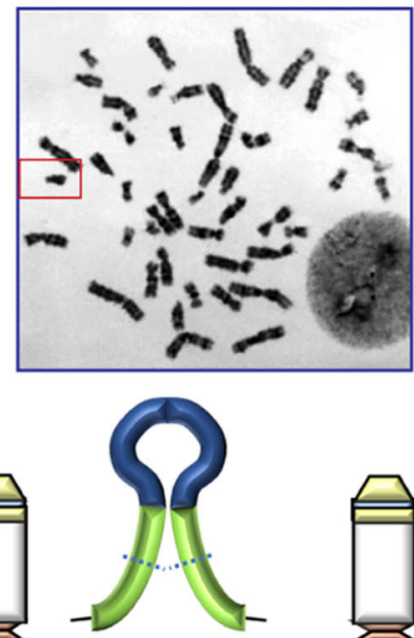

Aberrant recombination

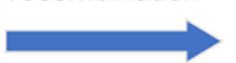

Deletion of intervening sequence

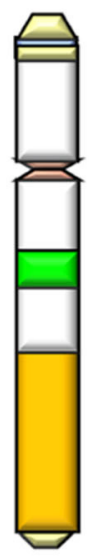

FIGURE 1 | Determinants of human sperm quality. (A) Micrograph of a typical human sperm population. Note the significant inter-cell variation in morphological appearance of the sperm head, midpiece and tail. Morphological assessments are generally couched in terms of percentage normal cells, however defining the precise attributes of "normal" in this context is difficult. Scale bar $=10 \mu \mathrm{m}$. (B) A clearly abnormal condition is "globozoospermia" characterized by round headed, acrosome-less cells that are incapable of fertilization even though their motility is normal (10). Scale bar $=10 \mu \mathrm{m}$. (C) In contrast, Kartgener syndrome is a genetically-determined condition associated with major defects in the axoneme and complete immotility. Left panel cross section through a normal sperm tail highlighting the dynein arms (arrowed); right panel shows a section through the axoneme of a Kartagener syndrome patient, showing the complete absence of dynein arms (11). Scale bar $=200 \mathrm{~nm}$ (D) Human karyotype with the Y-chromosome, framed. (E) Major mechanisms by which DNA fragmentation on the Y is induced is through the aberrant recombination of repetitive elements (green) and deletion of the intervening DNA (blue). 
with ICSI can enhance fertilization rates with globozoospermic spermatozoa, but even with this intervention success rates are still significantly lower than control levels (12). One possible explanation for the poor fertilization rates observed with such spermatozoa is that they apparently exhibit high levels of DNA fragmentation in association with poor chromatin packaging and protamine deficiency (13). A related syndrome is "partial globozoospermia" where $>50 \%$ of cells exhibit the round-headed acrosomeless morphology (14). Although the genetic basis of this partial condition remains uncertain at the present time, the presence of apparently normal cells in the ejaculate means that it can be very effectively treated with ICSI (15).

The causes of globozoospermia are genetic and, as far as we are currently aware, involve mutations in three genes, SPATA16 (spermatogenesis associated 16), PICK1 (protein interacting with PRKCA 1) and DPY19L2 (DPY-19 like 2) with the latter being dominant (16). Homozygous deletions in DPY19L2 are caused by non-allelic homologous recombination between flanking LCR (low copy repeat) sequences in around $70 \%$ of cases (17). Like most genetic conditions responsible for male infertility these causative mutations are rare $(<1 \%)$. The major DPY19L2 deletion is thought to have stabilized at a low level within the population because the de novo production of mutant alleles balances the negative selection incurred by sterile homozygous males (18).

A second sperm defect with a recognized genetic cause is macrozoospermia, characterized by the presence of a very high percentage of spermatozoa with enlarged heads and multiple flagella. A majority of such cells are diploid and the etiology involves mutations in the AURKC (aurora kinase C) gene (16). The incidence of these mutations varies from population to population but a recent analysis of North African males suggested that AURKC mutations were the most common, comprising $2.7 \%$ of the infertile male population compared with $1.2 \%$ exhibiting DPY19L2-dependent globozoospermia and anticipated rates of $1.6 \%$ exhibiting Klinefelter syndrome and $0.23 \%$ with Y-chromosome deletion (19). Macrozoospermia is observed in patients who are homozygous recessive for AURKC mutations. Two mutations in AURKC have been described: A p.Y248* non-sense mutation which arose 925-1,325 years ago and the c.144delC homozygous frameshift mutation, dated as having occurred 250-650 years ago. In order to account for the retention of these mutations in the population over so many generations, it has been suggested that the heterozygote must have some selective reproductive advantage possibly related to sperm production (20); however, there is no evidence to support this suggestion at present.

Sperm head morphology is also radically altered in a condition known as acephalic spermatozoa. Mutations in several different genes are known to generate this phenotype. Thus, polyamine modulated factor 1 binding protein 1 ( $P M F B P 1)$, testis specific 10 (TSGA10), Sad1 and UNC84 domain containing 5 (SUN5), bromodomain testis associated (BRDT) and centrosomal protein 112 (CEP112) have all recently been implicated in the etiology of this condition (21-23). The reason why so many different mutations appear to be involved in the creation of acephalic spermatozoa is a reflection of the inordinate complexity of the head-tail coupling apparatus in these cells (24). Mutations in SUN5 account for about half of all cases of acephalic spermatozoa in human patients. In some ways this is fortunate, because patients with SUN5 mutations can be successfully treated using ICSI (25), reflecting the very specific role this protein plays in anchoring the sperm head to the tail (26). However, other mutations associated with the acephalic syndrome such as TSGA10 and CEP112 are not readily treatable with assisted conception therapy because the damage is centered on the sperm centriole and, in humans, the paternal centrioles are responsible for orchestrating cell division in the embryo. In the absence of functional centrioles in the spermatozoa, fertilization may be achievable with ICSI but any embryo created will exhibit arrested embryonic development (22).

Just as the complexity of sperm head attachment means that the acephalic condition is potentially associated with mutations in any one of a number of key genes, exactly that same is true of defects in the flagellum in the etiology of asthenozoospermia. We have known about defects in the axoneme in the pathological suppression of sperm motility since the pioneering work of Afzelius $(27,28)$ recorded defects in several components of the axoneme of men exhibiting either a complete lack of sperm motility or severe asthenozoospermia. These diseases are grouped under the heading of primary ciliary dyskinesias (PCDs) because they affect all ciliary structures in the body, not just the sperm flagella. A classic example of this condition is Kartegener syndrome (Figure 1C), which is associated with a complete lack of sperm motility due to the absence of dynein arms, in association with chronic sinusitis, bronchiectasis and, in 50\% of cases, situs inversus caused by an inability of the embryonic cilia to shift the heart to the left hand side. The condition is inherited in an autosomal recessive manner as a result of biallelic homozygous or compound heterozygous mutations in several candidate genes including coiled-coil domain containing 40 (CCDC40), dynein axonemal heavy chain 1, 5, and 11 (DNAH1, DNAH5, DNAH7 DNAH11) dynein axonemal intermediate chain 1 (DNAI1), leucine rich repeat containing 6 (LRRC6), Zinc finger MYNDtype containing 10 (ZMYND10) armadillo repeat containing 4 (ARMC4) and tetratricopeptide repeat domain 12 (TTC12) (29-33). Overall, more than 40 genes have been implicated in this heterogenous disease to date and the list of genes involved is expanding rapidly in concert with improvements in our understanding of ciliary structure and function. In theory, any gene involved in the assembly, structure and function of ciliary/flagellar structures could contribute to the male infertility associated with PCD. The condition is rare (prevalence 1:10,000 to 1:40,000 births) and the ultrastructural phenotypes are variable involving no outer and inner dynein arms (DAs), outer DAs alone, inner DAs with microtubular disorganization or defects yielding an abnormal central complex. Because of this heterogeneity, not all patients exhibiting PCD are infertile. Importantly apart from the loss of motility, spermatozoa obtained from Kartagener syndrome have been shown to be functionally normal in that they will engage in the process of capacitation, will acrosome react and, if physically 
manipulated to lie close to the plasma membrane of the oocyte will achieve sperm-oocyte fusion (11). So, even if motility loss is total, conceptions can still be achieved using either sub-zonal insemination (SUZI) techniques that place immotile, but acrosome reacted, spermatozoa adjacent to the vitelline membrane of the oocyte or ICSI (34). Outside of such assisted conception procedures, spontaneous pregnancies are possible with PCD patients providing the loss of motility is partial; however, spontaneous fertility is unlikely with mutations in certain genes including CCDC39, CCDC40, dynein axonemal assembly factor 1 (DNAAF1) and LRRC6 (35).

In addition to $\mathrm{PCD}$, where multiple ciliopathies are observed in different organ systems, male infertility is also associated with sperm motility defects involving genes that specifically impact the development of the sperm tail, its detailed architecture and its physiological regulation. These mutations generate isolated male infertility associated with severe asthenozoospermia in the absence of any other pathology and are known collectively as Multiple Morphological Abnormalities of the sperm Flagella (MMAF). The list of mutations responsible for MMAF is expanding rapidly but currently includes mutations in adenylate kinase 7 (AK7) (36), glutamine rich 2 (QRICH2) (37), cilia and flagella associated proteins (CFAP43, CFAP44, CFAP65, CFAP69, CFAP70, CFAP91, CFAP251) (38-44) WD repeat domain 19 (WDR19) (45), DAZ interacting zinc finger protein (DZIP1) (46), DNAH1 (also implicated in PCD) (47) DNAH2 (48), DNAH6 (49), DNAH17 (50), TTC29 (51), TTC21A (52), armadillo repeat containing 2 (ARMC2) (53) CEP135 (centrosomal protein 135) (54). fibrous sheath interacting protein 2 (FSIP2) (55), ADP ribosylation factor like GTPase 2 binding protein $(A R L 2 B P)(56)$, sperm flagellar 2 (SPEF2) (57), and DnaJ heat shock protein family (Hsp40) member B13 (DNAJB13) (58).

Of course, motility is not the only attribute of sperm function susceptible to interference by genetic and epigenetic mutations. For example, we know that genetic defects in sperm PLC $\zeta$, which activates the generation of calcium transients in the fertilized oocyte, impair human oocyte activation and fertilization (59). Fertilization failure has also been associated with mutations in CATPSERE (CatSper-epsilon), a component of the sperm calcium channel (60) as well as polymorphisms in the mitochondrial genes MT-ATP6 and MT-CYB (61).

It must be evident from the information presented above that there are a great number of mutations potentially capable of suppressing the fertilizing potential of human spermatozoa. This may not be surprising given the biochemical sophistication underpinning such complex sperm functions as sperm motility (which accommodates a variety of sophisticated behaviors including rheotaxis, chemotaxis and thermotaxis as well as the switch to hyperactivation), sperm transport to the site of fertilization, the ability of a capacitated spermatozoon to recognize just one other cell type in the body (the egg), the induction of acrosomal exocytosis, sperm-oocyte fusion and oocyte activation. Moreover, these are just the mutations affecting the structure and function of spermatozoa, there are a great many more mutations influencing the primary production of spermatozoa at a testicular level.

\section{Mutations Affecting the Testes and Excurrent Ducts}

Obstructive azoospermia is present in around $30 \%$ of azoospermia cases and is often due to occlusion of the excurrent duct system subsequent to infection, trauma or surgery. The major genetic cause involves CFTR (Cystic fibrosis transmembrane conductance regulator) mutations that are known to induce abnormal formation or bilateral absence of the vas deferens (62). The remaining $70 \%$ of azoospermia cases are non-obstructive and relate to primary failure of spermatogenesis. Primary testicular failure may be observed with different forms of testicular cancer, the genetic origins of which are as complex as their histopathology, including germ cell tumors (seminoma, embryonal carcinoma, yolk sac tumor, and teratoma) and, in older men, testicular lymphomas $(63,64)$. Gains of chromosome arm 12p and aneuploidy are nearly universal in germ cell tumors (65) while primary testicular lymphomas involve near-uniform loss of CDKN2A (cyclin dependent kinase inhibitor 2A) with rare TP53 (tumor protein p53) mutations as well as 9p24.1/PDL1/PD-L2 copy number alterations and additional translocations of these loci (66).

Cancer aside, an increasing list of monogenic gene mutations are being associated with non-obstructive azoospermia. Just as we saw with mutations affecting sperm structure and function, gene mutations leading to primary testicular failure are many, varied and infrequent, reflecting the underlying complexity of the spermatogenic process and the inability of any particular mutation to become anything other than rare, given: (1) the negative selection pressure associated with male infertility, (2) the fact that many of these mutations also cause infertility in women and so cannot find refuge in the female germ line (67), and (3) the absence of any particular reproductive advantage in the heterozygous form. These mutations are generally autosomal recessive and inherited from fertile parents in homozygous, compound heterozygous or hemizygous form. However, autosomal dominant monogenic mutations can also precipitate a state of infertility including SYCP3 (Synaptonemal complex protein 3), NR5A1 (nuclear receptor subfamily 5 group A member 1) and the WT1 (Wilms' tumor 1) gene (68). A recent detailed analysis of the genetic causes of non-obstructive azoospermia (NOA) concluded that the largest single category of monogenic defects detected in NOA patients comprises genes involved in different stages of spermatogenesis, mostly functioning in the prophase of the first meiotic division as well as transcriptional and endocrine regulators of reproduction (67).

Of course, not all mutations causing non-obstructive azoospermia are expressed in the testes. There are several genes involved in the etiology of hypogonadotrophic hypogonadism that are key components of the hypothalamic-pituitary-gonadal axis involved in the endocrine regulation of spermatogenesis. The human GNRHR (gonadotropin-releasing hormone receptor) gene is a case in point. This protein is a G-protein coupled receptor expressed on the surface of pituitary gonadotrophs that respond to pulsatile GnRH stimulation by promoting the secretion of gonadotrophins FSH and LH. Several (at least 19) mutations have been identified in this gene that often exert 
their pathological action as compound heterozygotes (68). There are also mutations that interfere with the differentiation of the male reproductive system including cytochrome b5 type A (CYB5A) which selectively disrupts 17,20-lyase activity leading to disordered sexual development (69) and deletions on chromosome 21 that also cause defects in male sexual development (70). Mutations on the $\mathrm{X}$ chromosome are also linked with male infertility including: anosmin 1 (ANOS1), a gene linked to Kallmann syndrome (71), testis expressed 11 (TEX11), linked to meiotic arrest (72) and nuclear receptor subfamily 0 group B member 1 (NR0B1) associated with adrenal hyperplasia and hypogonadotropic hypogonadism (73). Mutations in the $\mathrm{X}$-linked androgen receptor gene are also known to induce infertility in around $2 \%$ of male patients (74).

Overall, the foregoing summary reveals a bewildering array of monogenic defects involved in male infertility exerting their action at all stages of gonadal development and function, from the initial morphogenesis of the male genital tract in the fetus to the differentiation and maturation of fully functional spermatozoa. However, interestingly, the most common genetic causes of male infertility are not single gene mutations at all, but aneuploidies of which Klinefelter syndrome (XXY) is the most common, accounting for around $10 \%$ of patients with non-obstructive azoospermia/severe oligozoospermia $(75,76)$.

In view of the strong negative selection pressure associated with infertility, the maintenance of such an impressive range of infertility-inducing chromosomal or genetic mutations in the general population must involve the steady spontaneous generation of de novo lesions affecting genes and chromosomes involved in the spermatogenic process (77). The importance of such de novo mutations in the etiology of male infertility is beautifully illustrated by the presence of Y-chromosome deletions in males exhibiting spontaneous severe oligozoospermia on nonobstructive azoospermia.

\section{THE Y CHROMOSOME}

The Y chromosome is unusual because it lives in isolation (Figure 1D). One detrimental consequence of such a solitary existence is that the $\mathrm{Y}$ chromosome has limited options when it comes to the repair of DNA damage. All other chromosomes have a homologous chromosome, inherited from the other parent, that can assist in the repair of damage DNA via homologous recombination. The $\mathrm{Y}$ chromosome has no homolog to recombine with and so it has reverted to an intrachromosomal form of recombination in order to maintain a modicum of stability. Typically, genes on the Y-chromosome make multiple copies of themselves as a buffer against the chaos that would be introduced by the accumulation of deleterious spontaneous mutations, a lack of selection pressure, the presence of unwanted genetic hitchhikers and genetic drift. Some of these repetitive elements have become inverted to create palindromic sequences that facilitate recombination events in an area of the genome where inter-chromosomal recombination is otherwise suppressed. As a consequence of this strategy, damage to key genes on the Y-chromosome can be repaired by the affected gene recombining with a palindromic copy of itself in a process known as gene conversion. This capacity for intra-chromosomal recombination has enabled the $\mathrm{Y}$ chromosome to stabilize after an initial period of exponential decay such that no genes have been lost since the divergence of humans and chimpanzees between 6 and 7 million years ago while only one gene had been lost since humans diverged from the rhesus macaque 25 million years ago $(78,79)$.

Unfortunately, the presence of such palindromic sequences, as well as repetitive retroviral elements on the human $\mathrm{Y}$ chromosome, facilitates the creation of chromosome deletions as a consequence of aberrant recombination events (Figure 1E). Three common Yq deletions that recur in infertile males are termed AZF (Azoospermia Factor) microdeletions-AZFa, AZFb and AZFc. In addition, the combinations, AZFbc, AZFabc, and a partial AZFc, called AZFc/gr/gr are also observed (80, 81). AZFa and $\mathrm{AZFb}$ deletions usually result in complete azoospermia, with no current potential for treatment. However, patients with AZFc deletions are typically characterized by severe oligozoospermia, with small numbers of spermatozoa recoverable from the ejaculate or from testicular biopsy material. These cells are sufficiently normal to permit treatment options involving ICSI. Of course, an inevitable consequence of the Y-chromosome's genetic isolation, is that any son generated as a consequence of ICSI will inherit his father's microdeletion and, thus, his infertility (80).

The prevalence of $\mathrm{Y}$ chromosome deletions and microdeletions is estimated at 1:2,000 to 1:3,000 males while the frequency of Yq microdeletions in males with azoospermia is $15 \%$ and with severe oligozoospermia about $5 \%$ (82). Unlike the monogenic gene mutations responsible for defective sperm production or primary testicular failure reviewed above, Y-chromosome mutations cannot be maintained in the population as heterozygotes or via passage through the female germ line. With very few exceptions, every new case of Y-chromosome deletion has been spontaneously created in the fertile father's germ line. This tells us that DNA damage and repair must be a major feature of male reproduction. Indeed, a recent analysis has found that $75 \%$ of all de novo mutations arise in the male germ line via mechanisms that have little to do with replication error, as commonly supposed (83). Rather, the high rate of mutations observed in the male germ line, including common C-to-G transversions and $\mathrm{CpG}$ transitions show genomic distributions and sexspecific age dependencies indicative of double-strand break repair and methylation-associated damage, respectively (83). The Y-chromosome's strategy of gene amplification and intra-chromosomal recombination in order to stabilize has, undeniably, been effective in slowing the rate of gene attrition on this chromosome. However, the presence of so many repetitive palindromic elements also creates a measure of vulnerability. If DNA fragmentation rates are high, then there is the potential for distant palindromic sequences to recombine, resulting in deletion of the intervening genetic information. Such deletions could either occur during spermatogenesis or, in principle, in the oocyte as a result of aberrant DNA repair prior to the S-phase that precedes the first cleavage division. Thus, Y-chromosome deletions, like many mutations that arise in our species may 
be seen as a consequence of the high rates of DNA damage and fragmentation that characterize the male germline. In this context, there is a significant body of evidence indicating that DNA fragmentation is a consistent feature of human spermatozoa and that the induction of such damage is oxidative.

\section{OXIDATIVE STRESS}

The importance of oxidative stress in the etiology of defective sperm function has been recognized since the pioneering studies of Thaddeus Mann and colleagues at the University of Cambridge demonstrated that mammalian spermatozoa were vulnerable to a lipid peroxidation process that attacks the unsaturated fatty acids in these cells, destroying the plasma membrane and compromising their functional competence (84). The induction of such stress may involve the enhanced generation of reactive oxygen species (ROS) by these cells and/or a deficiency in the levels of antioxidant protection they are afforded (85-87). The net impacts of oxidative stress include a loss of motility, a decrease in the ability of the spermatozoa to undergo the acrosome reaction, an impaired capacity to fuse with the vitelline membrane of the oocyte-and DNA damage (85, 88-90).

\section{Leukocyte Infiltration and ROS Generation}

The sources of ROS that create this oxidative stress are complex and may be due to either intrinsic or extrinsic factors. The major extrinsic factor are leukocytes that enter the semen at the moment of ejaculation from the secondary sexual glands. The major leukocyte species in this context are neutrophils (Figure 2A) that arrive in the seminal compartment in an activated, free radical-generating state (Figure $\mathbf{2 B}$ ). The presence of these cells is thought to reflect an underlying reproductive tract infection $(92,93)$, although other factors such as trauma, surgery, and autoimmunity could also be involved. As long as leukocyte numbers are relatively low (less than the leukocytospermic threshold of 1 million/ml), the ROS generated by infiltrating leukocytes have no effect on the functionality of the spermatozoa because these cells are adequately protected by the powerful antioxidants present in seminal plasma (94). However, if the leukocyte numbers exceed this leukocytospermic threshold, or are just below it, then a state of oxidative stress prevails, and sperm function is compromised (95). Furthermore, if leukocytes are still present in the washed sperm suspensions used in assisted conception procedures then significant oxidative stress will again be created due to the absence of significant antioxidant protection in conventional IVF culture media. The existence of low-level leukocyte contamination in washed human sperm suspensions is a significant issue for IVF therapy because it negatively impacts the fertilization rates subsequently observed $(96,97)$. This problem can either be addressed through the incorporation of antioxidants such as $\mathrm{N}$-acetylcysteine or hypotaurine in the culture medium (98) and/or through the selective removal of contaminating leukocytes using magnetic particles coated with a monoclonal antibody against the common leukocyte antigen (Figure 2C) (91). Such treatments effectively reduce levels of oxidative stress in the sperm suspensions and significantly enhance the fertilization rates subsequently observed.

\section{Spermatozoa and ROS Generation}

Outside of leukocyte contamination, a majority of the ROS that compromise sperm function are generated endogenously via a variety of pathways, in response to a variety of stimuli. It is important to point out that the levels of ROS generated by spermatozoa are orders of magnitude lower than leukocytes (99). This is the reason why flow cytometry is such a useful technique for monitoring seminal ROS production because it enables the separation of spermatozoa from other cell types and simplifies interpretation of the data. By contrast, techniques such as luminometry, always run the risk of generating data that is heavily influenced by the presence of contaminating leukocytes $(100,101)$. It should also be recognized that a vast majority of the probes used with flow cytometry are redox active agents that do not measure ROS directly but rather, oxidative activity. Nevertheless, by using dihydroethidium as a probe and separating out the reaction product specifically generated by superoxide anion, 2-hydroxyethidium, it has been possible to generate evidence of superoxide production by mammalian spermatozoa $(102,103)$. Moreover, these data have been confirmed with definitive techniques such as electron paramagnetic resonance spectroscopy (104-106).

There has also been discussion as to which ROS is the more important in the determination of sperm function, superoxide (107) hydrogen peroxide $(86,108-110)$ nitric oxide (111) or peroxynitrite (112). In reality, all these oxidants and free radical species are so reactive that they are constantly interconverting and contributing to the oxidative stress experienced by the male gamete. It is doubtful whether any particular species actually pre-dominates.

\section{Sperm Mitochondria as a Source of ROS}

One of the major sources of superoxide anion within spermatozoa are the mitochondria (113). These organelles generate ROS as a normal by-product of aerobic metabolism due to the leakage of electrons from the mitochondrial electron transport chain, which are then swept up by the universal electron acceptor, oxygen, to generate superoxide anion. Mitochondrial ROS are also produced as part of the intrinsic apoptotic cascade that becomes activated whenever the phosphoinositide signaling pathway is compromised (114). Under physiological circumstances, a variety of pro-survival factors, including as insulin, prolactin or angiotensin 1-7 $(115,116)$ stimulate phosphorylation and activation of phosphoinositide- 3 kinase (PI3K). The latter in turn phosphorylates another kinase, AKT. As long as AKT is phosphorylated, downstream targets of this kinase such as the apoptosis regulator, BCL2-associated-agonistof-cell-death (BAD) are also phosphorylated. Phospho-BAD forms a heterodimer with its 14-3-3 keeper protein, leaving Bcl-2 free to inhibit Bax-triggered apoptosis, thereby maintaining spermatozoa a viable motile state (114). However, if PI3K activity is disrupted, AKT and its downstream target, BAD, become dephosphorylated allowing the latter to escape from the grip of its 14-3-3 keeper to form a heterodimer with Bcl-2 and $\mathrm{Bcl}-\mathrm{xL}$, inactivating these regulators and thus allowing Bax/Bak-triggered apoptosis. The intrinsic apoptotic cascade is associated with rapid motility loss, mitochondrial ROS 
A

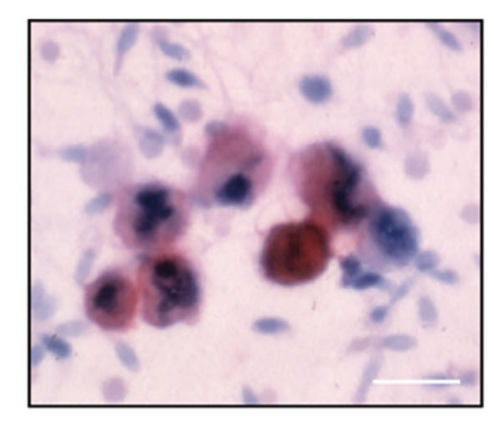

C

Leucocytes

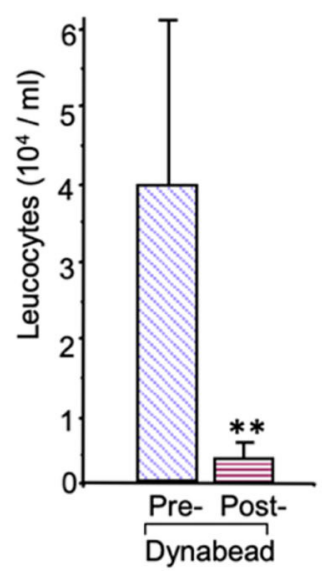

B

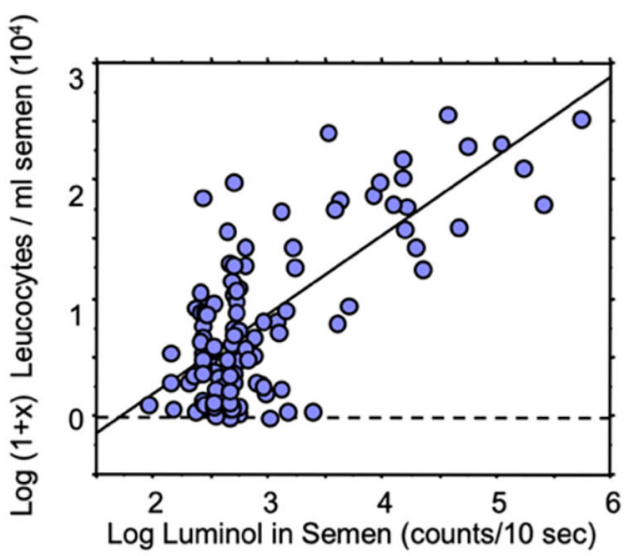

FIGURE 2 | Leukocyte contamination of human semen samples. (A) All human semen samples are contaminated with leukocytes, largely neutrophils, and macrophages; sample stained with an antibody against the common leukocyte antigen, CD45. Sale bar = 10 $\mu \mathrm{m}$. (B) The spontaneous generation of reactive oxygen species by human semen samples is highly correlated with the level of leukocyte contamination. (C) Treatment of washed human sperm suspensions with magnetic beads coated in anti-DC45 removes a majority of the leukocytes, reduces the levels of oxidative stress as determined by luminol dependent chemiluminescence and increases fertilization rate in the heterologous sperm-oocyte fusion assay (91). ${ }^{\star} P<0.05$; ${ }^{\star \star} P<0.01$.

generation, caspase activation in the cytosol, annexin $\mathrm{V}$ binding to the cell surface, cytoplasmic vacuolization and oxidative DNA damage (Figure 3) (114). So, any stress factor that will induce an apoptotic response in human spermatozoa will trigger mitochondrial ROS generation and a loss of sperm function.

Mitochondrial ROS generation and apoptosis may also be important in the mechanisms underpinning sperm senescence. All mammalian spermatozoa have a finite life span and after a few days (depending on species) will become senescent in vivo and in vitro, losing their vitality, motility, tyrosine phosphorylation status and DNA integrity with the passage of time $(117,118)$. Oxidative stress appears to be one component of the senescence process judging from the fact that sperm motility and DNA integrity can be significantly improved in vitro if oxygen tensions are reduced and/or antioxidants are incorporated into the medium (119-121). Furthermore, the generation of ROS on prolonged incubation has been found to increase with time and a majority of this ROS appears to be mitochondrial, possibly reflecting the progressive entry of senescent cells into the intrinsic apoptotic pathway $(121,122)$. Accordingly, antioxidants that target mitochondrial ROS generation such as co-enzyme Q10 and pyrroloquinoline quinone as well as thiols such as $\mathrm{N}$ acetylcysteine and penicillamine have been found to extend sperm motility in vitro $(121,123,124)$. Similarly, treatments that divert energy generation away from mitochondrial oxidative phosphorylation and toward glycolysis, such as exposure to rosiglitazone, decrease mitochondrial ROS generation, and allow spermatozoa to maintain high levels of motility in vitro for at least 6 days (125). However, there is still some conjecture as to how many other factors are involved in sperm motility loss in vitro. In a recent study of human spermatozoa incubated over a 5 day period, the loss of virtually all motility was not accompanied by a corresponding increase in 4 -HNE levels by Western blot (102). In light of these data, we have to conclude that there may be multiple 


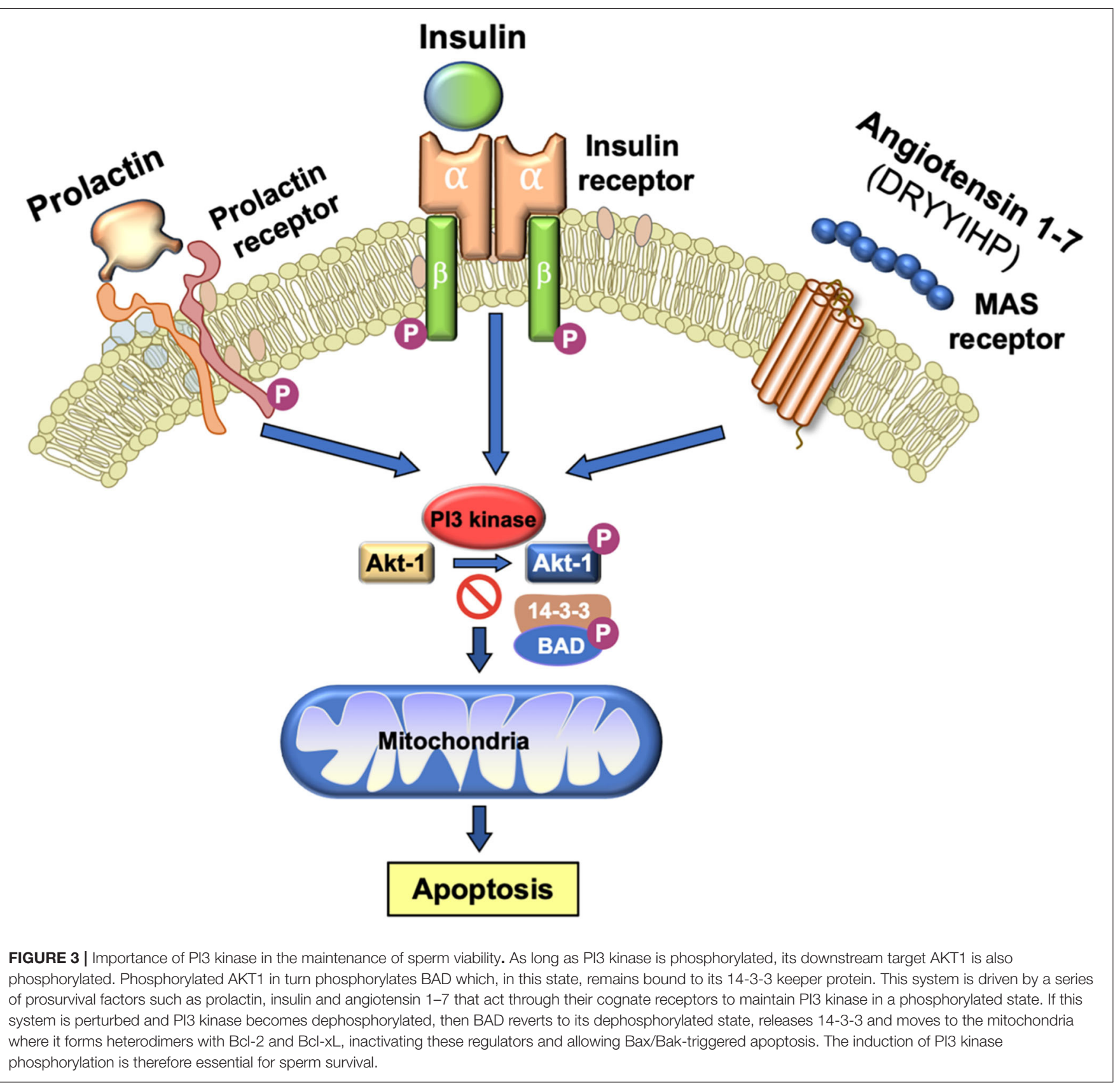

reasons why spermatozoa become senescent in vitro and we are yet to resolve the full complexities of this process.

Mitochondrial ROS can also be triggered by a range of amphiphilic compounds in human spermatozoa including cisunsaturated fatty acids; the polar nature of these compounds favoring their corporation into mitochondrial membranes, altering membrane fluidity and facilitating electron leakage (126). Since the free unsaturated fatty acid content of defective human sperm populations is positively correlated with the induction of mitochondrial superoxide generation, we can conclude that the pathophysiology of defective sperm function is at least partly dependent on changes to the lipid composition of these cells
(127). Mitochondrial ROS can also be stimulated by toxicants that can perturb the flow of electrons along the mitochondrial electron transport chain. For example, the common preservative, parabens (a mixture of parabenzoic esters), has been shown to stimulate mitochondrial ROS in spermatozoa in a manner which is correlated with alkyl chain length (128). Similarly, the xenoestrogen bisphenol A stimulates mitochondrial ROS generation by human sperm mitochondria (129) as do certain polyphenols (epigallocatechin gallate, genistein, didox gossypol) several of which are traditionally regarded as antioxidants (130).

The cryopreservation of spermatozoa is another situation in which sperm function is compromised partly as a consequence 
of oxidative stress created by enhanced mitochondrial ROS generation. Consequently, a large number of studies, conducted in a range of different species, have examined the impact of antioxidants on post-thaw functionality. Since antioxidants such as L-carnitine and Mito Tempo have already proven effective in this regard $(131,132)$, a systematic comparison of antioxidants targeting the mitochondria is now warranted, to determine the optimal formulation for protecting spermatozoa against cryostorage injury.

Another extraneous factor which is thought to enhance mitochondrial ROS generation in mammalian spermatozoa is radiofrequency electromagnetic radiation (RFEMR) (133). The concept that RFMR induces electron leakage from the mitochondrial electron transport chain, and thus promotes superoxide anion generation (134), is controversial but has received support from numerous independent studies (135). Mitochondrial ROS generation activated by RFEMR has, in turn, been associated with the suppression of sperm motility, the induction of apoptosis, the loss of local antioxidant protection and the stimulation of sperm oxidative DNA damage both in vivo and in vitro (136-140).

In vitro exposure to electromagnetic radiation in the form of UVB light will also trigger mitochondrial ROS generation in human spermatozoa (141) as will the in vitro exposure of these cells to temperatures above $40^{\circ} \mathrm{C}(134)$. Mild heat stress $\left(35^{\circ} \mathrm{C}\right)$ has also been found to activate mitochondrial ROS generation in vivo, with round spermatids being particularly vulnerable to this form of stress (135).

Mitochondrial ROS generation can also be stimulated by the electrophilic lipid aldehydes generated as an end-product of lipid peroxidation. Not all lipid aldehydes are equivalent in this respect, the differences generally correlating with the second order rate constants describing their interaction with the model nucleophile, glutathione. Acrolein and 4hydroxynonenal (4-HNE) are the most active, stimulating mitochondrial ROS generation by binding to components of the mitochondrial electron transport chain, particularly succinic acid dehydrogenase $(142,143)$. The capacity of lipid aldehydes generated as a result of oxidative stress to bind to components of the mitochondrial electron transport chain and stimulate yet more ROS generation means that once this process is initiated, it becomes a self-perpetuating process unless a chain breaking antioxidant intervenes.

\section{NAD(P)H Oxidase}

Another potential source of ROS generation in human spermatozoa are $\mathrm{NAD}(\mathrm{P}) \mathrm{H}$ oxidases reminiscent of the enzyme responsible for the oxidative burst in phagocytic leukocytes. Several authors $(144,145)$ have suggested that spermatozoa generate ROS via such enzymes based on the inhibitory action of diphenylene iodonium (DPI). However, DPI is a generalized flavoprotein inhibitor and so also suppresses ROS generation by oxidoreductases in the mitochondrial electron transport chain. This, and other factors, has, in some minds, cast doubt on the existence of such an enzyme in human spermatozoa and its possible contribution to oxidative stress in the male germ line $(146,147)$. However, in 2002, Banfi et al. (148) described the existence of an NADPH oxidase (NOX5) in several cell types, including human spermatozoa. Musset et al. (149) subsequently confirmed immunocytochemically that this oxidase was not only present in the neck or acrosomal region of these cells but generated superoxide anion in a calciumdependent manner. They also identified cAbl as a tyrosine kinase associated with the activation of this oxidase. In addition, exposure to hydrogen peroxide was found to activate ROS generation by NOX5. These findings explain why several authors (150-152) have found that sustained ROS generation by human spermatozoa can be triggered by transient exposure to an oxidizing agent such as hydrogen peroxide-it also provides a mechanism. ROS generation is known to be associated with the stimulation of tyrosine phosphorylation in mammalian spermatozoa through the suppression of tyrosine phosphatase activity and the activation of adenylyl cyclase (153-155). cAMP is, in turn, known to activate cAbl in spermatozoa (156), and this kinase would then be expected to activate NOX5 leading to yet more ROS generation in concert with sperm capacitation, which is also cAMP driven (Figure 4).

The clinical significance of NOX5 is indicated by its high level of expression in the spermatozoa of asthenozoospermic males in concert with increases in superoxide and hydrogen peroxide generation and DNA damage (157). NOX5 expression has also been shown to be elevated in cases of teratozoospermia (158). Physiologically, the $\mathrm{H}(\mathrm{V}) 1$ proton channel, which has been implicated in the regulation of sperm motility, is required for optimal superoxide production by spermatozoa via NOX5 (149), presumably by preventing cytoplasmic acidification that inevitably follows NADPH oxidation:

$$
\begin{aligned}
\mathrm{NADPH}+ & 2 \mathrm{O}_{2} \Rightarrow \mathrm{NADP}^{+}+2 \mathrm{O}_{2}^{-\bullet}+\mathrm{H}^{+} \\
& \text {NADPH oxidase superoxide proton }
\end{aligned}
$$

Moreover, there is evidence that NOX5 and $\mathrm{H}(\mathrm{V}) 1$ are involved in the induction of calcium signaling via Catsper in response to progesterone stimulation (159), again reflecting the fact that the activity of this calcium channel is highly sensitive to changes in $\mathrm{pH}$ (160) and that NOX 5 achieves intracellular alkalinization by activating the $\mathrm{H}(\mathrm{V}) 1$ proton channel. Thus, it is possible that that NOX5 is a key regulator of sperm function as well as a potential mediator of oxidative stress and sperm pathology (Figure 4). However, we do not yet know why NOX5 activity would be elevated in the spermatozoa of infertile males. It is possible that the supply of NADPH is rate limiting in this situation and that cells possessing a large amount of residual cytoplasm (a characteristic feature of defective human spermatozoa suffering from oxidative stress) could fuel oxidase activity because they are over-endowed with glucose-6-phosphate dehydrogenase, a key regulator of the hexose monophosphate shunt responsible for regulating NADPH generation (161). We also do not understand how mouse spermatozoa can exhibit the same relationship between cAMP, ROS generation and sperm capacitation (162) but do not possess NOX5-possibly other oxidases are active in this species. 


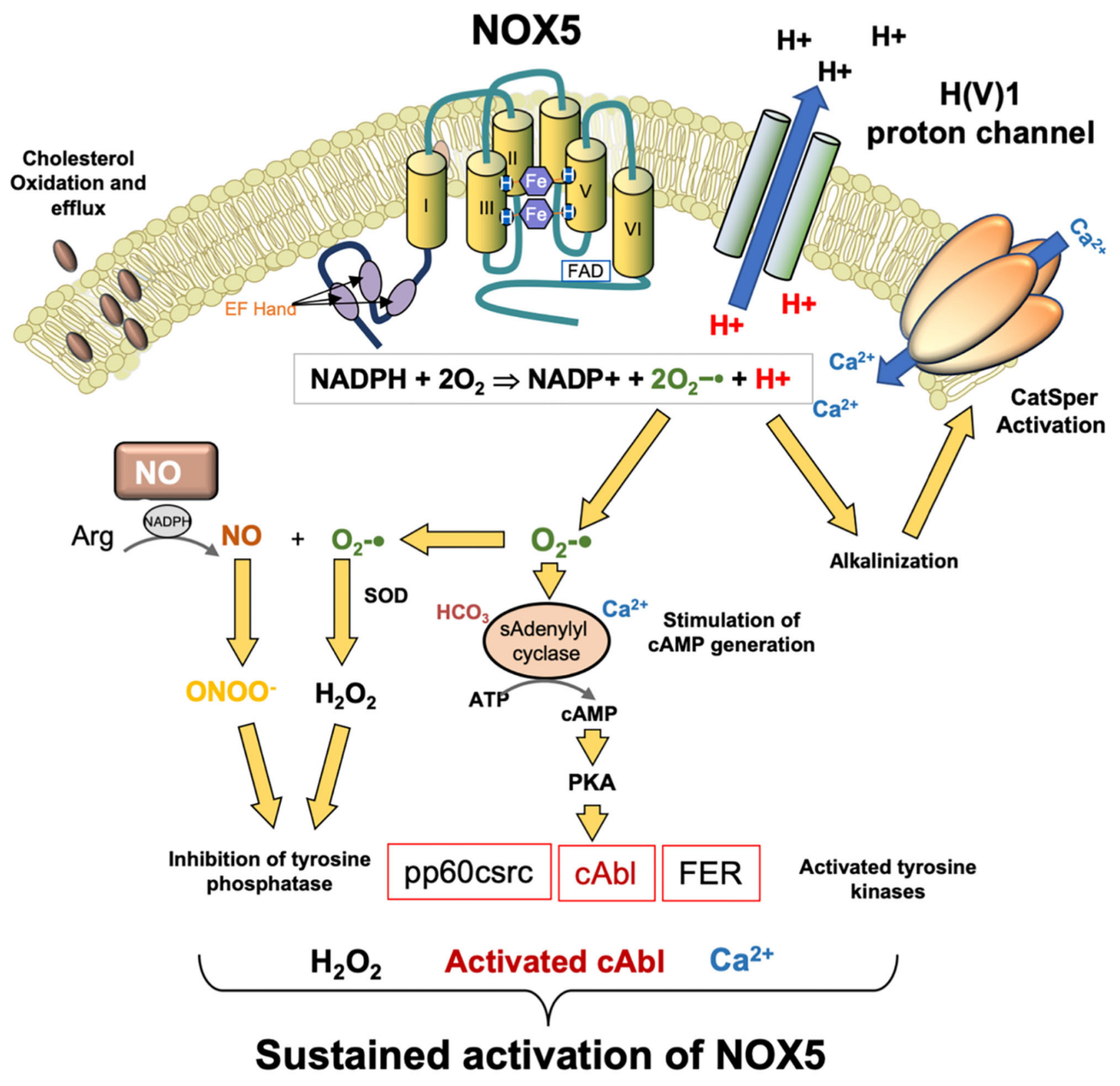

\section{Sustained increase in tyrosine phosphorylation}

\section{$\checkmark$ \\ Capacitation}

FIGURE 4 | Potential role for NOX5 in the regulation of sperm capacitation. NOX5 catalyzes the generation of superoxide anion and protons. The latter activate the $\mathrm{H}(\mathrm{N}) 1$ proton channel leading to proton extrusion and alkalinization of the cytoplasm. This $\mathrm{pH}$ change activates the CatSperm channel leading to calcium influx which in turn further promotes NOX5 activity. The other product of NOX5 action, superoxide anion participates tin the activation of soluble adenylyl cyclase and the generation of CAMP. cAMP activates PKA which then phosphorylates as number of tyrosine kinases. At the same time, hydrogen peroxide and peroxynitrite (ONOO-) co-operate to silence tyrosine phosphatase activity leading to a global increased in phosphotyrosie expression. One of the kinases activated in this process, cAbl, as well as hydrogen peroxide, are both known to stimulate NOX5 activity. As a consequence of these activities, NOX5 is maintained in an activated state, driving the tyrosine phosphorylation cascades that culminate in the attainment of a capacitated state. 


\section{Lipoxygenase}

Another factor in the oxidative stress equation that may be upregulated in spermatozoa possessing excess residual cytoplasm is lipoxygenase. This enzyme is present in cytoplasmic droplets of defective spermatozoa (163) and catalyzes the dioxygenation of polyunsaturated fatty acids to the corresponding hydroperoxide. The enzyme facilitates the initial hydrogen abstraction step in the peroxidation process, creating a lipid radical that then combines with molecular oxygen to create a peroxyl radical that on protonation generates the corresponding hydroperoxide. There are two ways in which this chemistry could be associated with oxidative stress. The first is that in the presence of $\mathrm{NADPH}$, lipoxygenases can generate superoxide anion directly (164). Pharmacological inhibition of the lipoxygenase, ALOX15, in precursor male germ cells and spermatozoa results in a significant reduction in both mitochondrial and cytoplasmic ROS generation, as well as a dramatic reduction in 4-HNE accumulation $(165,166)$. These findings are consistent with the ability of polyunsaturated fatty acids to stimulate ROS generation in human spermatozoa and thereby compromise sperm function (126). The second means by which excess lipoxygenase activity could create oxidative stress in these cells is by fueling the generation of lipid hydroperoxides in the sperm plasma membrane. These peroxides have the potential to initiate a lipid peroxidation cascade if sufficient transition metals (e.g., iron, copper) are present in the immediate vicinity (167). If left unbroken, such peroxidative chain reactions culminate in the generation of electrophilic lipid aldehydes such as 4-HNE which can have a devastating impact on sperm function by binding to key proteins involved in the execution of sperm function. In this context, incubating human spermatozoa in the presence of a lipoxygenase inhibitor has been shown to both reduce the levels of 4-HNE accumulation in human spermatozoa and promote the functional competence of these cells (166).

\section{L-amino Acid Oxidase}

The first enzyme that was ever shown to generate ROS in mammalian spermatozoa was an L-amino acid oxidase. In their landmark papers published more than 70 years ago, Tosic and Walton $(168,169)$ described the presence of an enzyme in bovine spermatozoa that generated significant quantities of hydrogen peroxide using aromatic acids, such as phenylalanine. Interestingly dead cells were more responsive to phenylalanine stimulation because the disrupted plasma membrane allowed this amino acid substrate access to the oxidase. So, when bovine spermatozoa were exposed to high concentrations of aromatic amino acids (as happens when these cells are suspended in cryostorage media supplemented with egg yolk) the dead cells generated high amounts of hydrogen peroxide which then impeded the motility and fertilizing potential of live cells in the immediate vicinity. The same oxidase has been detected in equine (170), ovine (171), and human spermatozoa (172). In the latter, oxidase activity was lost from non-viable cells, so the "dead cell-influencing-live cell" scenario established for ungulate spermatozoa does not apply in the human situation. The physiological purpose of the oxidase is currently unclear, although in the presence of phenylalanine human spermatozoa develop many of the hallmarks of capacitation, including increased tyrosine phosphorylation and enhanced acrosome rates, via mechanisms that could be reversed by the concomitant presence of catalase. It is therefore possible that this enzyme contributes to the redox regulation of capacitation as spermatozoa ascend the female reproductive tract (172)-always assuming the bioavailability of adequate quantities of aromatic amino acids in this location.

\section{Antioxidant Protection}

Spermatozoa possess very little cytoplasm and, as a consequence, they are deficient in the antioxidant enzymes that protect most cells from oxidative stress. This does not mean that these cells are totally lacking in any form of intracellular protection because they do possess a number of important antioxidant enzymes such as peroxiredoxin 6, superoxide dismutase, the glutathione peroxidase-reductase couple and limited catalase (86, 173-175). However, the level of protection afforded by these systems has finite limits with the result that spermatozoa are heavily dependent on extracellular antioxidants present the seminiferous tubule fluid (176) epididymal plasma (177), seminal plasma (178) and uterotubal fluid (179) to provide them with complete protection during their voyage from the seminiferous tubules to the vitelline membrane of the oocyte. As a result, any factors that impact the overall antioxidant status of an individual, and thus the bioavailability of extracellular antioxidants, can have an impact on the levels of oxidative stress suffered by the male germ line and thence fertility $(180,181)$. Examples of such conditions include diet (182), varicocele (183) smoking (184), obesity (185), heat stress (186), and environmental toxicants such as bisphenol A (187) all of which can impact systemic antioxidant tone and thus the vulnerability of spermatozoa to oxidative stress. Inadequate intracellular and extracellular antioxidant protection could therefore be a major factor in the etiology of both male infertility and oxidative DNA damage to the paternal genome (188). Given this background it would seem axiomatic that if oxidative stress is such a powerful cause of reproductive dysfunction in the male, then antioxidants should be part of the cure $(189,190)$. Unfortunately, the clinical trials needed to demonstrate that the administration of antioxidants to patients suffering demonstrable oxidative stress in their germ line will reap a therapeutic reward, have not yet been conducted at scale. Some promising pilot studies have been conducted with positive results (191) and efficacy has clearly been demonstrated in animal models (190). However, the gold standard randomized, double-blind, cross-over, placebo-controlled trial has yet to be conducted, partly because there is currently no consensus over the oxidative stress markers that should be used to identify appropriate patients for antioxidant therapy.

\section{Other Therapeutic Interventions}

In addition to antioxidant administration we should also recognize that a variety of lifestyle interventions might also influence the oxidative stress underpinning male infertility including, increased exercise, improved diet as well as the cessation of alcohol consumption and cigarette smoking. Interestingly, the practice of yoga has been found to have a 
positive impact on the mRNA profile of human spermatozoa, their epigenetic status, the generation of ROS, the levels of DNA damage in the sperm nucleus and various attributes of the conventional semen profile $(192,193)$. Such results suggest that male infertility may have a strong psychogenic component which can be ameliorated by yoga-based lifestyle interventions aimed at reducing cognitive, as well as oxidative, stress.

\section{Oxidative Stress and Embryo Development}

While we have traditionally viewed male reproductive competence in terms of fertilization capacity, it is now clear that the definition of "competence" should extend beyond conception to encompass the establishment of a normal viable pregnancy as well as the health and well-being of the offspring. It is therefore important to acknowledge that oxidative damage to human spermatozoa does not just influence their capacity for fertilization but also has a major impact on the developmental potential of the embryo (194, 195). Importantly, when spermatozoa are subjected to increasing levels of oxidative stress, the induction of significant DNA damage precedes the loss of fertilizing potential (196). As a consequence, it is perfectly possible for a DNA damaged spermatozoon to achieve fertilization of the oocyte. When this happens, the oocyte immediately launches into a round of DNA repair in order to address any damage in the paternal genome prior to the initiation of S-phase of the first mitotic cell division. If the oocyte makes a mistake at this point or is overwhelmed by the levels of DNA damage brought in by the fertilizing spermatozoon, it has the potential to increase mutations in the offspring that may significantly impact the latter's developmental potential and long-term health trajectory.

Oocytes are particularly vulnerable to the introduction of oxidative DNA damage by the fertilizing spermatozoon because they are deficient in the first enzyme of the base excision repair pathway, OGG-1 (197). Typically, defective human spermatozoa carry extremely high levels of oxidative DNA damage $(198,199)$ so the chances are, that fertilization will force the oocyte to the very limits of its repair capacity. Persistence of paternallyderived oxidized DNA base adducts into S-phase of the first mitotic division will enhance the risk of de novo mutations being created as the embryos enter the cleavage stage of development. Experimentally, if gametes are generated expressing high levels of oxidative DNA damage by genetically inactivating the major base excision DNA repair pathways, then the offspring exhibit high levels of de novo mutations, particularly $\mathrm{G}$ to $\mathrm{T}$ transversions, and live lives shortened by birth defects and disease, including cancer (200). Oxidative stress in the male germ line can therefore not only create de novo mutations directly; it can also generate pre-mutational damage that becomes fixed as a genetic mutation following fertilization, as a result of deficient or aberrant repair in the oocyte prior to the first cleavage division (82). It has recently been recognized that while most age-related de novo mutations are paternal in origin, there is also a powerful maternal contribution (83). We hypothesize that this maternal factor could be the negative impact of age on the DNA repair capacity in the oocyte (201). Viewed in this light, the creation of de novo mutations could be regarded, at least in part, as a collusion between the male and female germ lines. In the male germ line, we see extensive evidence of oxidative DNA damage, the incidence of damage increasing with age as the DNA repair capacity of the germ line declines. This oxidatively damaged DNA is then brought into the oocyte by the fertilizing sperm, overwhelming the latter's capacity for effective DNA repair and stimulating the creation of de novo mutations that ultimately impact the health and well-being, and potentially the fertility, of the offspring.

\section{A Unifying Concept: Oxidative DNA Damage, Infertility and Offspring Health}

So, we have a male infertility landscape which, until recently has been largely unexplained. However, in the past decade or so, it has become clear that both genetics and oxidative stress play important roles in the definition of semen quality. In the final section of this review we ask whether these two epidemiological pathways might be causally linked.

Clearly oxidative stress in the male germ line can be driven by a great many environmental, lifestyle and clinical factors ranging from smoking, obesity, electromagnetic radiation including heat, a variety of xenobiotic toxicants including the omnipresent phthalate esters and bisphenol A, varicocele, infection and autoimmunity [(202, 203); Figure 5]. As germ cells differentiate, they become progressively less adept at DNA repair and this ineptness only increases with paternal age (204). The oxidative damage sustained by these cells will, if it is sufficiently intense, suppress the fertilizing capacity of the spermatozoa by impairing their motility and their capacity for interaction with the oocyte (85). If the damage is less intense, these cells may still retain their capacity for fertilization and thus have the ability to carry oxidatively damaged DNA (194) and, potentially, oxidatively damaged centrioles (205) and telomeres (206) (guanine rich structures at the end of chromosomes that are known to be paternally inherited and vulnerable to oxidative stress), into the oocyte, all of which could disrupt embryonic development, implantation and the progress of pregnancy to term. Genetic and epigenetic mutations induced via this mechanism have the potential to impact the fertility, health and well-being of the offspring.

In terms of infertility, the DNA fragmentation precipitated by the induction of oxidative stress has the potential to create Y chromosome deletions through aberrant recombination of the repetitive sequences that abound on this chromosome. Stochastic point mutations introduced by such means also have the potential to induce infertility if they interfere with expression of key genes involved in orchestrating the production and differentiation of spermatozoa. The complex nature of these cells ensures that there are plenty of genes to choose from.

We have recently reported that when spermatozoa are exposed to an oxidative stress, DNA damage is generated across the genome as one might have anticipated, although the sex chromosomes are to some degree protected. Against this background there is, however, one area of the human sperm genome that is particularly vulnerable to oxidative attack on chromosome 15 (207). Such susceptible genomic sites 


\section{Pathology in the offspring}

\section{Factors affecting male reproduction}

\section{Miscarriage, dominant} genetic disease, Complex brain disorders, cancer, metabolic disease

\section{Paternal age, diet, infection, electromagnetic radiation, occupational, environmental exposure to metals or complex organics, genetic disposition s,}

Aberrant or deficient DNA
Mutations or epimutations affecting male fertility

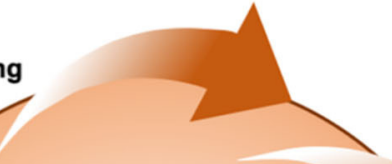

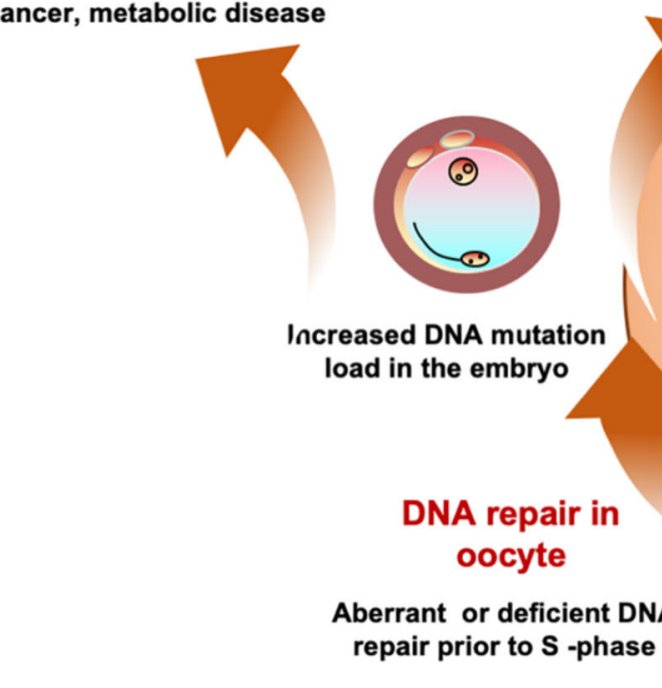
repair prior to $S$-phase

(1)

\author{
(1)
}

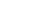


associated with male infertility that were covered in the first part of this review, involve chromosome 15. Whether the observed mutations are involved in the central endocrine drive to spermatogenesis, the process of spermatogenesis itself or the production of morphologically normal motile spermatozoa capable of fertilization, they occur in virtually every part of the genome but not chromosome 15. Perhaps this is too vulnerable an area of the genome to sequester genes that are critical to reproductive success.

However, chromosome 15 does encode a number of genes involved neurological development. The very area of the genome that we have found to be vulnerable to oxidative attack is also the site of genetic perturbations associated with a variety of brain disorders including Marfan syndrome, epilepsy, spontaneous schizophrenia, bipolar disease, attention deficit hyperactivity disorder and, critically, autism (213). Interestingly, all of these conditions are highly correlated with the age of the father at the moment of conception. Since paternal age is associated with oxidative stress in the male germ line, we hypothesize that an agerelated oxidative attack on the paternal germ line precipitated the mutations that ultimately led to these conditions appearing in the offspring (Figure 5).

Of course, aging is just one way of creating oxidative stress in germ cells, there are many others not least of which is infertility itself. Since male infertility is commonly associated with the kind of oxidative stress we associate with aging, we might anticipate an increase in conditions such as autism in the offspring of ART patients, particularly when ICSI is used as the insemination procedure. In keeping with this proposition, a report from the USA did indeed find an increased risk of autism in the progeny when ICSI, not IVF, was used to inseminate the oocytes (214). Similarly, the area of chromosome 15 which is vulnerable to oxidative attack also houses the imprinted genes responsible for Prader-Willi and Angelman syndromes and evidence exists to suggest that both of these conditions may elevated in the offspring of subfertile couples and may be exacerbated by assisted conception therapy (215). Although this association between assisted conception therapy and imprinting disorders is not consistently observed across all datasets, the 3.44-fold increase in Prader Willi syndrome observed by Hattori et al. (215) is particularly striking and could be explained by oxidative destruction of the paternal allele, allowing the maternal allele to dominate. Interestingly, deletions in this area of the genome are thought to involve DNA fragmentation followed by aberrant recombination of flanking repeat elements (ENDrepeats), in much the same way as deletions are induced on the Y-chromosome (216).

Smoking is another condition associated with oxidative stress in the male germ line, that is independent of age and generates $8 \mathrm{OHdG}$ lesions in human spermatozoa via mechanisms that can be exacerbated by antioxidant deficient diets and OGG1 Ser326Cys polymorphisms $(217,218)$. There are also data to indicate a significant association between paternal smoking and cancer in the offspring, particularly leukemias including acute lymphoblastic leukemia (219). Consistent with the data presented above, it is of interest that one of the loci associated with childhood leukemia is on chromosome 15 (15q13-15)
(220). Fundamentally, oxidative DNA damage induced in human spermatozoa as a result of heavy smoking is probably responsible of introducing millions of de novo mutations into our species (221), with implications for the future incidence of childhood leukemias (and possibly other conditions) in affected lineages.

The genomic domain we have identified as being particularly susceptible to oxidative damage is known to be a hot spot for copy number variation (222) and microdeletions in $15 \mathrm{q} 11.2$ BP1-BP2 (the Burnside-Butler susceptibility locus) are known to associated with intellectual impairment (223). Thus, oxidative damage to this area of the genome in human spermatozoa may be associated with a range of phenotypes in the offspring including male infertility, imprinting disorders and a plethora of behavioral/intellectual defects. Any conditions that promote oxidative damage in human spermatozoa may increase the incidence of such conditions in the offspring depending on the severity and location of the damage and the efficiency of DNA repair.

\section{CLINICAL SIGNIFICANCE}

What is the clinical significance of all this information? Fundamentally, this review is intended to highlight the potential significance of oxidative stress in both the etiology of male infertility and the mutational load subsequently carried by the offspring. The management of male infertility patients should therefore involve an assessment by the levels of oxidative stress and DNA damage suffered by the spermatozoa. If these parameters are elevated, then, and only then, should interventions be considered. The most obvious therapeutic intervention would be to give affected patients antioxidants and then monitor the levels of oxidative stress over time to ensure that this approach (or the particular antioxidant product selected) is being effective. It is important not to give antioxidants in the absence of a diagnosis of oxidative stress in order to avoid the induction of reductive stress, which can be just as damaging as its oxidative counterpart. From a preventative standpoint, it would also be important to carefully review the patient's medical history, occupation and lifestyle in an attempt to identify potential causes of the oxidative stress which could be addressed. Thus, the presence of a varicocele, infection, sedentary lifestyle, obesity, lack of exercise, poor diet, high scrotal temperatures, excessive consumption of recreational drugs including alcohol and tobacco and psychological stress, are all possible contributors to oxidative stress in infertility patients that might be addressed by simple lifestyle interventions. As far as genetic factors are concerned, the management options are more challenging because the damage has already been done in the germlines of the patients' forebearers and, in the absence of gene therapy, the only realistic option is IVF/ICSI. While this form treatment has enjoyed some success, knowing the genetic basis of the infertility (particularly for the most common genetic conditions such as cystic fibrosis gene mutations, Klinefelter syndrome, Y chromosome microdeletions, Noonan syndrome, and chromosomal translocations) may be important in counseling the patients on the likely health trajectory of their offspring and the possible benefits of using 
donor spermatozoa. See Ferlin and Foresta (224) for further detailed discussion of these issues from a clinical perspective.

\section{CONCLUSION}

In conclusion. a variety of environmental and lifestyle factors including age, smoking, infertility, obesity, exposure to a range of xenobiotic toxicants, radiofrequency electromagnetic radiation, heat and cryopreservation $(213,225,226)$ conspire to generate oxidative DNA damage and fragmentation in the male germline. Inefficient or aberrant repair then fixes this damage as a mutation, either in the germline itself or in the newly fertilized oocyte. Mutations generated in this way can cause infertility in male offspring as a consequence of Y-chromosome deletions or a wide range of mutations in other parts of the genome that influence the production or functionality of the spermatozoa. In addition, these mutations can cause a range of other diseases particularly cancer and brain disorders, including autism and

\section{REFERENCES}

1. Aitken RJ. The male is significantly implicated as the cause of unexplained infertility. Sem Reprod Med. (2020). [Epub ahead of print].

2. Aitken RJ, Irvine DS, Wu FC. Prospective analysis of spermoocyte fusion and reactive oxygen species generation as criteria for the diagnosis of infertility. Am J Obstet Gynecol. (1991) 164:542-51. doi: 10.1016/S0002-9378(11)80017-7

3. Kini S, Morrell D, Thong KJ, Kopakaki A, Hillier S, Irvine DS. Lack of impact of semen quality on fertilization in assisted conception. Scott Med J. (2010) 55:20-3. doi: 10.1258/RSMSMJ.55.1.20

4. Irvine DS, Aitken RJ. Predictive value of in-vitro sperm function tests in the context of an AID service. Hum Reprod. (1986) 1:53945. doi: 10.1093/oxfordjournals.humrep.a136470

5. Sukcharoen N, Keith J, Irvine DS, Aitken RJ. Prediction of the in-vitro fertilization (IVF) potential of human spermatozoa using sperm function tests: the effect of the delay between testing and IVF. Hum Reprod. (1996) 11:1030-4. doi: 10.1093/oxfordjournals.humrep.a019291

6. Bostofte E, Serup J, Rebbe H. Relation between sperm count and semen volume, and pregnancies obtained during a twenty-year follow-up period. Int J Androl. (1982) 5:267-75. doi: 10.1111/j.1365-2605.1982.tb0 0255.x

7. Wallace EM, Aitken RJ, Wu FC. Residual sperm function in oligozoospermia induced by testosterone enanthate administered as a potential steroid male contraceptive. Int J Androl. (1992) 15:416-24. doi: 10.1111/j.1365-2605.1992.tb01356.x

8. Cooper TG, Noonan E, von Eckardstein S, Auger J, Baker HW, Behre HM, et al. World health organization reference values for human semen characteristics. Hum Reprod Update. (2010) 16:23145. doi: 10.1093/humupd/dmp048

9. Zinaman MJ, Brown CC, Selevan SG, Clegg ED. Semen quality and human fertility: a prospective study with healthy couples. J Androl. (2000) 21:145-53.

10. Aitken RJ, Kerr L, Bolton V, Hargreave T. Analysis of sperm function in globozoospermia: implications for the mechanism of sperm-zona interaction. Fertil Steril. (1990) 54:701-7. doi: 10.1016/S0015-0282(16)53 833-3

11. Aitken RJ, Ross A, Lees MM. Analysis of sperm function in kartagener's syndrome. Fertil Steril. (1983) 40:6968. doi: 10.1016/S0015-0282(16)47434-0

12. Tavalaee M, Nomikos M, Lai FA, Nasr-Esfahani MH. Expression of sperm PLC $\zeta$ and clinical outcomes of ICSI-AOA in men affected by globozoospermia due to DPY19L2 deletion. Reprod Biomed Online. (2018) 36:348-355. doi: 10.1016/j.rbmo.2017.12.013 spontaneous schizophrenia. This tentative unifying hypothesis is summarized in Figure 5 and provides us with a model we can test in future studies.

\section{AUTHOR CONTRIBUTIONS}

RJA prepared the first draft of the manuscript which was then critically reviewed by MB. Both authors approve the final version and submission of this article.

\section{FUNDING}

We gratefully acknowledge the support of the University of Newcastle and the Priority Research Centre for Reproductive Science. MB is recipient of a Senior Research Fellowship from the NHMRC.
13. Talebi AR, Ghasemzadeh J, Khalili MA, Halvaei I, Fesahat F. Sperm chromatin quality and DNA integrity in partial versus total globozoospermia. Andrologia. (2018) 50:1. doi: 10.1111/and.12823

14. Dam AH, Ramos L, Dijkman HB, Woestenenk R, Robben H, van den Hoven L, et al. Morphology of partial globozoospermia. J Andro. (2011) 32:199-206. doi: 10.2164/jandrol.109.009530

15. Dam AH, Pijnenburg AJ, Hendriks JC, Westphal H, Ramos L, Kremer JA. Intracytoplasmic sperm injection in partial globozoospermia. Fertil Steril. (2012) 97:60-6. doi: 10.1016/j.fertnstert.2011.10.003

16. De Braekeleer M, Nguyen MH, Morel F, Perrin A. Genetic aspects of monomorphic teratozoospermia: a review. J Assist Reprod Genet. (2015) 32:615-23. doi: 10.1007/s10815-015-0433-2

17. Elinati E, Kuentz P, Redin C, Jaber S, Vanden Meerschaut F, Makarian J, et al. Globozoospermia is mainly due to DPY19L2 deletion via non-allelic homologous recombination involving two recombination hotspots. Hum Mol Genet. (2012) 21:3695-702. doi: 10.1093/hmg/dds200

18. Coutton C, Abada F, Karaouzene T, Sanlaville D, Satre V, Lunardi $J$, et al. Fine characterisation of a recombination hotspot at the DPY19L2 locus and resolution of the paradoxical excess of duplications over deletions in the general population. PLoS Genet. (2013) 9:e1003363. doi: 10.1371/journal.pgen.1003363

19. Ounis L, Zoghmar A, Coutton C, Rouabah L, Hachemi M, Martinez D, et al. Mutations of the aurora kinase $\mathrm{C}$ gene causing macrozoospermia are the most frequent genetic cause of male infertility in Algerian men. Asian J Androl. (2015) 17:68-73. doi: 10.4103/1008-682X.136441

20. Ben Khelifa M, Coutton C, Blum MG, Abada F, Harbuz R, Zouari R, et al. Identification of a new recurrent aurora kinase $\mathrm{C}$ mutation in both European and African men with macrozoospermia. Hum Reprod. (2012) 27:3337-46. doi: 10.1093/humrep/des296

21. Liu G, Wang $\mathrm{N}$, Zhang $\mathrm{H}$, Yin S, Dai H, Lin G, et al. Novel mutations in PMFBP1, TSGA10 and SUN5: expanding the spectrum of mutations that may cause acephalic spermatozoa. Clin Genet. (2020) 97:9389. doi: $10.1111 /$ cge.13747

22. Nie H, Tang Y, Qin W. Beyond acephalic spermatozoa: the complexity of intracytoplasmic sperm injection outcomes. Biomed Res Int. (2020) 2020:6279795. doi: 10.1155/2020/6279795

23. Sha Y, Wang X, Yuan J, Zhu X, Su Z, Zhang X, et al. Loss-of-function mutations in centrosomal protein 112 is associated with human acephalic spermatozoa phenotype. Clin Genet. (2020) 97:321-8. doi: 10.1111/cge.13662

24. Wu B, Gao H, Liu C, Li W. The coupling apparatus of the sperm head and tail. Biol Reprod. (2020) 102:988-98. doi: 10.1093/biolre/ioaa016

25. Fang J, Zhang J, Zhu F, Yang X, Cui Y, Liu J. Patients with acephalic spermatozoa syndrome linked to SUN5 mutations have 
a favorable pregnancy outcome from ICSI. Hum Reprod. (2018) 33:372-7. doi: 10.1093/humrep/dex382

26. Shang Y, Zhu F, Wang L, Ouyang YC, Dong MZ, Liu C, et al. Essential role for SUN5 in anchoring sperm head to the tail. eLife. (2017) 6:e28199. doi: 10.7554/eLife.28199

27. Afzelius BA. The immotile-cilia syndrome and other ciliary diseases. Int Rev Exp Pathol. (1979) 19:1-43. doi: 10.1016/S0022-5320(79)80041-6

28. Afzelius BA. Genetical and ultrastructural aspects of the immotile-cilia syndrome. Am J Hum Genet. (1981) 33:852-64.

29. Zariwala MA, Gee HY, Kurkowiak M, Al-Mutairi DA, Leigh MW, Hurd TW, et al. ZMYND10 is mutated in primary ciliary dyskinesia and interacts with LRRC6. Am J Hum Genet. (2013) 93:336-45. doi: 10.1016/j.ajhg.2013.06.007

30. Onoufriadis A, Shoemark A, Munye MM, James CT, Schmidts M, Patel $M$, et al. Combined exome and whole-genome sequencing identifies mutations in ARMC4 as a cause of primary ciliary dyskinesia with defects in the outer dynein arm. J Med Genet. (2014) 51:61-7. doi: 10.1136/jmedgenet-2013-101938

31. Pereira R, Barbosa T, Gales L, Oliveira E, Santos R, Oliveira J, et al. Clinical and genetic analysis of children with Kartagener syndrome. Cells. (2019) 8:E900. doi: 10.3390/cells8080900

32. Yue Y, Huang Q, Zhu P, Zhao P, Tan X, Liu S, et al. Identification of pathogenic mutations and investigation of the notch pathway activation in Kartagener syndrome. Front Genet. (2019) 10:749. doi: 10.3389/fgene.2019.00749

33. Thomas L, Bouhouche K, Whitfield M, Thouvenin G, Coste A, Louis B, et al. TTC12 loss-of-function mutations cause primary ciliary dyskinesia and unveil distinct dynein assembly mechanisms in motile cilia versus flagella. Am J Hum Genet. (2020) 106:153-69. doi: 10.1016/j.ajhg.2019.12.010

34. Nijs M, Vanderzwalmen P, Vandamme B, Segal-Bertin G, Lejeune $B$, Segal L, et al. Fertilizing ability of immotile spermatozoa after intracytoplasmic sperm injection. Hum Reprod. (1996) 11:2180-5. doi: 10.1093/oxfordjournals.humrep.a019073

35. Vanaken GJ, Bassinet L, Boon M, Mani R, Honoré I, Papon JF, et al. Infertility in an adult cohort with primary ciliary dyskinesia: phenotype-gene association Eur Respir J. (2017) 50:1700314. doi: 10.1183/13993003.00314-2017

36. Lorès $\mathrm{P}$, Coutton $\mathrm{C}$, El Khouri E, Stouvenel L, Givelet M, Thomas L, et al. Homozygous missense mutation L673P in adenylate kinase 7 (AK7) leads to primary male infertility and multiple morphological anomalies of the flagella but not to primary ciliary dyskinesia. Hum Mol Genet. (2018) 27:1196-211. doi: 10.1093/hmg/ddy034

37. Kherraf ZE, Cazin C, Coutton C, Amiri-Yekta A, Martinez G, Boguenet $\mathrm{M}$, et al. Whole exome sequencing of men with multiple morphological abnormalities of the sperm flagella reveals novel homozygous QRICH2 mutations. Clin Genet. (2019) 96:394-401. doi: 10.1111/cge.13604

38. Li W, He X, Yang S, Liu C, Wu H, Liu W, et al. Biallelic mutations of CFAP251 cause sperm flagellar defects and human male infertility. J Hum Genet. (2019) 64:49-54. doi: 10.1038/s10038-018-0520-1

39. He X, Li W, Wu H, Lv M, Liu W, Liu C, et al. Novel homozygous CFAP69 mutations in humans and mice cause severe asthenoteratospermia with multiple morphological abnormalities of the sperm flagella. J Med Genet. (2019) 56:96-103. doi: 10.1136/jmedgenet-2018-105486

40. Beurois J, Martinez G, Cazin C, Kherraf ZE, Amiri-Yekta A, ThierryMieg N, et al. CFAP70 mutations lead to male infertility due to severe astheno-teratozoospermia. A case report. Hum Reprod. (2019) 34:20719. doi: 10.1093/humrep/dez166

41. Zhang X, Shen Y, Wang X, Yuan G, Zhang C, Yang Y. A novel homozygous CFAP65 mutation in humans causes male infertility with multiple morphological abnormalities of the sperm flagella. Clin Genet. (2019) 96:541-8. doi: 10.1111/cge.13644

42. Wu H, Li W, He X, Liu C, Fang Y, Zhu F, et al. Novel CFAP43 and CFAP44 mutations cause male infertility with multiple morphological abnormalities of the sperm flagella (MMAF). Reprod Biomed Online. (2019) 38:76978. doi: 10.1016/j.rbmo.2018.12.037

43. Li L, Feng F, Wang Y, Guo J, Yue W. Mutational effect of human CFAP43 splice-site variant causing multiple morphological abnormalities of the sperm flagella. Andrologia. (2020) 52:e13575. doi: 10.1111/and.13575
44. Martinez G, Beurois J, Dacheux D, Cazin C, Bidart M, Kherraf ZE, et al. Biallelic variants in MAATS1 encoding CFAP91, a calmodulinassociated and spoke-associated complex protein, cause severe asthenoteratozoospermia and male infertility. J Med Genet. (2020) S1698031X(19)30081-0. doi: 10.1136/jmedgenet-2019-106775

45. Ni X, Wang J, Lv M, Liu C, Zhong Y, Tian S, et al. A novel homozygous mutation in WDR19 induces disorganization of microtubules in sperm flagella and nonsyndromic asthenoteratospermia. J Assist Reprod Genet. (2020) 37:1431-9. doi: 10.1007/s10815-020-01770-1

46. Lv M, Liu W, Chi W, Ni X, Wang J, Cheng H, et al. Homozygous mutations in DZIP1 can induce asthenoteratospermia with severe MMAF. J Med Genet. (2020) 57:445-53. doi: 10.1136/jmedgenet-2019-106479

47. Sha Y, Yang X, Mei L, Ji Z, Wang X, Ding L, et al. DNAH1 gene mutations and their potential association with dysplasia of the sperm fibrous sheath and infertility in the Han Chinese population. Fertil Steril. (2017) 107:13128.e2. doi: 10.1016/j.fertnstert.2017.04.007

48. Li Y, Sha Y, Wang X, Ding L, Liu W, Ji Z, et al. DNAH2 is a novel candidate gene associated with multiple morphological abnormalities of the sperm flagella. Clin Genet. (2019) 95:590-600. doi: 10.1111/cge.13525

49. Tu C, Nie H, Meng L, Yuan S, He W, Luo A, et al. Identification of DNAH6 mutations in infertile men with multiple morphological abnormalities of the sperm flagella. Sci Rep. (2019) 9:15864. doi: 10.1038/s41598-019-52436-7

50. Sha Y, Wei X, Ding L, Mei L, Huang X, Lin S, et al. DNAH17 is associated with asthenozoospermia and multiple morphological abnormalities of sperm flagella. Ann Hum Genet. (2020) 84:271-9. doi: 10.1111/ahg.12369

51. Liu C, He X, Liu W, Yang S, Wang L, Li W, et al. Bi-allelic mutations in TTC29 cause male subfertility with asthenoteratospermia in humans and mice. Am J Hum Genet. (2019) 105:1168-81. doi: 10.1016/j.ajhg.2019.10.010

52. Liu W, He X, Yang S, Zouari R, Wang J, Wu H, et al. Bi-allelic mutations in TTC21A induce asthenoteratospermia in humans and mice. Am J Hum Genet. (2019) 104:738-48. doi: 10.1016/j.jhg.2019.02.020

53. Coutton C, Martinez G, Kherraf ZE, Amiri-Yekta A, Boguenet M, Saut A, et al. Bi-allelic mutations in ARMC2 lead to severe astheno-teratozoospermia due to sperm flagellum malformations in humans and mice. Am J Hum Genet. (2019) 104:331-40. doi: 10.1016/j.ajhg.2018.12.013

54. Sha YW, Xu X, Mei LB, Li P, Su ZY, He XQ, et al. A homozygous CEP135 mutation is associated with multiple morphological abnormalities of the sperm flagella (MMAF). Gene. (2017) 633:48-53. doi: 10.1016/j.gene.2017.08.033

55. Martinez G, Kherraf ZE, Zouari R, Fourati Ben Mustapha S, Saut A, PernetGallay $\mathrm{K}$, et al. Whole-exome sequencing identifies mutations in FSIP2 as a recurrent cause of multiple morphological abnormalities of the sperm flagella. Hum Reprod. (2018) 33:1973-84. doi: 10.1093/humrep/dey264

56. Moye AR, Bedoni N, Cunningham JG, Sanzhaeva U, Tucker ES, Mathers P, et al. Mutations in ARL2BP, a protein required for ciliary microtubule structure, cause syndromic male infertility in humans and mice. PLoS Genet. (2019) 15:e1008315. doi: 10.1371/journal.pgen.1008315

57. Tu C, Nie H, Meng L, Wang W, Li H, Yuan S, et al. Novel mutations in SPEF2 causing different defects between flagella and cilia bridge: the phenotypic link between MMAF and PCD. Hum Genet. (2020) 139:25771. doi: 10.1007/s00439-020-02110-0

58. Li WN, Zhu L, Jia MM, Yin SL, Lu GX, Liu G. Missense mutation in DNAJB13 gene correlated with male fertility in asthenozoospermia. Andrology. (2020) 8:299-306. doi: 10.1111/andr.12685

59. Yuan P, Yang C, Ren Y, Yan J, Nie Y, Yan L, et al. A novel homozygous mutation of phospholipase $\mathrm{C}$ zeta leading to defective human oocyte activation and fertilization failure. Hum Reprod. (2020) 35:97785. doi: 10.1093/humrep/dez293

60. Brown SG, Miller MR, Lishko PV, Lester DH, Publicover SJ, Barratt CLR, et al. Homozygous in-frame deletion in CATSPERE in a man producing spermatozoa with loss of CatSper function and compromised fertilizing capacity. Hum Reprod. (2018) 33:1812-6. doi: 10.1093/humrep/dey278

61. Mao GH, Wang YN, Xu M, Wang WL, Tan L, Tao SB. Polymorphisms in the MT-ATP6 and MT-CYB genes in in vitro fertilization failure. Mitochondrial DNA. (2015) 26:20-4. doi: 10.3109/19401736.2013.840612

62. Lissens W, Mercier B, Tournaye H, Bonduelle M, Férec C, Seneca S, et al. Cystic fibrosis and infertility caused by congenital bilateral absence of 
the vas deferens and related clinical entities. Hum Reprod. (1996) 11(Suppl. 4):55-80. doi: 10.1093/humrep/11.suppl_4.55

63. Twa DDW, Mottok A, Savage KJ, Steidl C. The pathobiology of primary testicular diffuse large B-cell lymphoma: implications for novel therapies. Blood Rev. (2018) 32:249-55. doi: 10.1016/j.blre.2017.12.001

64. Shen H, Shih J, Hollern DP, Wang L, Bowlby R, Tickoo SK, et al. Integrated molecular characterization of testicular germ cell tumors. Cell Rep. (2018) 23:3392-406. doi: 10.1016/j.celrep.2018.05.039

65. Taylor-Weiner A, Zack T, O’Donnell E, Guerriero JL, Bernard B, Reddy A, et al. Genomic evolution and chemoresistance in germ-cell tumours. Nature. (2016) 540:114-8. doi: 10.1038/nature20596

66. Chapuy B, Roemer MG, Stewart C, Tan Y, Abo RP, Zhang L, et al. Targetable genetic features of primary testicular and primary central nervous system lymphomas. Blood. (2016) 127:869-81. doi: 10.1182/blood-2015-10-6 73236

67. Kasak L, Laan M. Monogenic causes of non-obstructive azoospermia: challenges, established knowledge, limitations and perspectives. Hum Genet. (2020). doi: 10.1007/s00439-020-02112-y

68. Jedidi I, Ouchari M, Yin Q. Autosomal single-gene disorders involved in human infertility. Saudi J Biol Sci. (2018) 25:8817. doi: 10.1016/j.sjbs.2017.12.005

69. Auchus RJ. Steroid 17-hydroxylase and 17,20-lyase deficiencies, genetic and pharmacologic. J Steroid Biochem Mol Biol. (2017) 165:71-8. doi: 10.1016/j.jsbmb.2016.02.002

70. Alkhalaf M, Verghese L, Muharib N. A cytogenetic study of Kuwaiti couples with infertility and reproductive disorders: short arm deletion of chromosome 21 is associated with male infertility. Ann Genet. (2002) 45:1479. doi: 10.1016/S0003-3995(02)01110-3

71. Gonçalves CI, Fonseca F, Borges T, Cunha F, Lemos MC. Expanding the genetic spectrum of ANOS1 mutations in patients with congenital hypogonadotropic hypogonadism. Hum Reprod. (2017) 32:704-711. doi: 10.1093/humrep/dew354

72. Yatsenko AN, Georgiadis AP, Röpke A, Berman AJ, Jaffe T, Olszewska $\mathrm{M}$, et al. X-linked TEX11 mutations, meiotic arrest, and azoospermia in infertile men. N Engl J Med. (2015) 372:2097-107. doi: 10.1056/NEJMoa14 06192

73. Vargas MCC, Moura FS, Elias CP, Carvalho SR, Rassi N, Kunii IS, et al. Spontaneous fertility and variable spectrum of reproductive phenotype in a family with adult-onset X-linked adrenal insufficiency harboring a novel DAX-1/NR0B1 mutation. BMC Endocr Disord. (2020) 20:21. doi: 10.1186/s12902-020-0500-2

74. Ferlin A, Vinanzi C, Garolla A, Selice R, Zuccarello D, Cazzadore C, et al. Male infertility and androgen receptor gene mutations: clinical features and identification of seven novel mutations. Clin Endocrinol. (2006) 65:60610. doi: 10.1111/j.1365-2265.2006.02635.x

75. Kim SY, Lee BY, Oh AR, Park SY, Lee HS, Seo JT. Clinical, hormonal, and genetic evaluation of idiopathic nonobstructive azoospermia and Klinefelter syndrome patients. Cytogenet Genome Res. (2017) 153:1907. doi: $10.1159 / 000487039$

76. Gumus E, Kati B, Pelit ES, Ordek E, Ciftci H. A different look at genetic factors in individuals with non-obstructive azoospermia or oligospermia in our research study: to whom, which threshold, when, in what way? Rev Int Androl. (2020). doi: 10.1016/j.androl.2019.08.001

77. Salahshourifar I, Gilani MA, Vosough A, Tavakolzadeh T, Tahsili $\mathrm{M}$, Mansori $\mathrm{Z}$, et al. De novo complex chromosomal rearrangement of $46, \mathrm{XY}, \mathrm{t}(3 ; 16 ; 8)(\mathrm{p} 26 ; \mathrm{q} 13 ; \mathrm{q} 21.2)$ in a non-obstructive azoospermic male. J Appl Genet. (2007) 48:93-4. doi: 10.1007/BF0319 4664

78. Hughes JF, Skaletsky H, Pyntikova T, Minx PJ, Graves T, Rozen S, et al. Conservation of Y-linked genes during human evolution revealed by comparative sequencing in chimpanzee. Nature. (2005) 437:1003. doi: 10.1038/nature04101

79. Bachtrog D. Y-chromosome evolution: emerging insights into processes of Y-chromosome degeneration. Nat Rev Genet. (2013) 14:113-24. doi: 10.1038/nrg3366

80. Colaco S, Modi D. Genetics of the human Y chromosome and its association with male infertility. Reprod Biol Endocrinol. (2018) 16:14. doi: 10.1186/s12958-018-0330-5
81. Li Z, Haines CJ, Han Y. Micro-deletions of the human Y chromosome and their relationship with male infertility. J Genet Genomics. (2008) 35:1939. doi: $10.1016 /$ S1673-8527(08)60027-2

82. Aitken RJ, Krausz C. Oxidative stress, DNA damage and the Y chromosome. Reproduction. (2001) 122:497-506. doi: 10.1530/reprod/122.4.497

83. Gao Z, Moorjani P, Sasani TA, Pedersen BS, Quinlan AR, Jorde LB, et al. Overlooked roles of DNA damage and maternal age in generating human germline mutations. Proc Natl Acad Sci USA. (2019) 116:9491500. doi: 10.1073/pnas.1901259116

84. Jones R, Mann T, Sherins R. Peroxidative breakdown of phospholipids in human spermatozoa, spermicidal properties of fatty acid peroxides, and protective action of seminal plasma. Fertil Steril. (1979) 31:5317. doi: 10.1016/S0015-0282(16)43999-3

85. Aitken RJ, Clarkson JS, Fishel S. Generation of reactive oxygen species, lipid peroxidation, and human sperm function. Biol Reprod. (1989) 41:18397. doi: 10.1095/biolreprod41.1.183

86. Alvarez JG, Touchstone JC, Blasco L, Storey BT. Spontaneous lipid peroxidation and production of hydrogen peroxide and superoxide in human spermatozoa. Superoxide dismutase as major enzyme protectant against oxygen toxicity. J Androl. (1987) 8:338-48. doi: 10.1002/j.1939-4640.1987.tb00973.x

87. Pasqualotto FF, Sharma RK, Nelson DR, Thomas AJ, Agarwal A. Relationship between oxidative stress, semen characteristics, and clinical diagnosis in men undergoing infertility investigation. Fertil Steril. (2000) 73:45964. doi: 10.1016/S0015-0282(99)00567-1

88. Aitken RJ, Clarkson JS, Hargreave TB, Irvine DS, Wu FC. Analysis of the relationship between defective sperm function and the generation of reactive oxygen species in cases of oligozoospermia. J Androl. (1989) 10:21420. doi: 10.1002/j.1939-4640.1989.tb00091.x

89. Griveau JF, Dumont E, Renard P, Callegari JP, Le Lannou D. Reactive oxygen species, lipid peroxidation and enzymatic defence systems in human spermatozoa. J Reprod Fertil. (1995) 103:17-26. doi: 10.1530/jrf.0.1030017

90. Aitken RJ, De Iuliis GN. Origins and consequences of DNA damage in male germ cells. Reprod Biomed Online. (2007) 14:727-33. doi: 10.1016/S1472-6483(10)60676-1

91. Aitken RJ, Buckingham DW, West K, Brindle J. On the use of paramagnetic beads and ferrofluids to assess and eliminate the leukocytic contribution to oxygen radical generation by human sperm suspensions. Am J Reprod Immunol. (1996) 35:541-51. doi: 10.1111/j.1600-0897.1996.tb00055.x

92. Aitken RJ, Baker MA. Oxidative stress, spermatozoa and leukocytic infiltration: relationships forged by the opposing forces of microbial invasion and the search for perfection. J Reprod Immunol. (2013) 100:119. doi: 10.1016/j.jri.2013.06.005

93. Fraczek M, Kurpisz M. Mechanisms of the harmful effects of bacterial semen infection on ejaculated human spermatozoa: potential inflammatory markers in semen. Folia Histochem Cytobiol. (2015) 53:201-17. doi: 10.5603/fhc.a2015.0019

94. Aitken RJ, West K, Buckingham D. Leukocytic infiltration into the human ejaculate and its association with semen quality, oxidative stress, and sperm function. J Androl. (1994) 15:343-52.

95. Saleh RA, Agarwal A, Kandirali E, et al. Leukocytospermia is associated with increased reactive oxygen species production by human spermatozoa. Fertil Steril. (2002) 78:1215-24. doi: 10.1016/S0015-0282(02)04237-1

96. Krausz C, Mills C, Rogers S, Tan SL, Aitken RJ. Stimulation of oxidant generation by human sperm suspensions using phorbol esters and formyl peptides: relationships with motility and fertilization in vitro. Fertil Steril. (1994) 62:599-605. doi: 10.1016/S0015-0282(16)56952-0

97. Sukcharoen N, Keith J, Irvine DS, Aitken RJ. Predicting the fertilizing potential of human sperm suspensions in vitro: importance of sperm morphology and leukocyte contamination. Fertil Steril. (1995) 63:1293300. doi: 10.1016/S0015-0282(16)57614-6

98. Baker HW, Brindle J, Irvine DS, Aitken RJ. Protective effect of antioxidants on the impairment of sperm motility by activated polymorphonuclear leukocytes. Fertil Steril. (1996) 65:411-9. doi: 10.1016/S0015-0282(16)58109-6

99. Armstrong JS, Bivalacqua TJ, Chamulitrat W, Sikka S, Hellstrom WJ. A comparison of the NADPH oxidase in human sperm and white blood cells. Int J Androl. (2002) 25:223-9. doi: 10.1046/j.1365-2605.2002.00351.x 
100. Aitken RJ, West KM. Analysis of the relationship between reactive oxygen species production and leucocyte infiltration in fractions of human semen separated on percoll gradients. Int J Androl. (1990) 13:43351. doi: 10.1111/j.1365-2605.1990.tb01051.x

101. Aitken RJ, Baker MA, O’Bryan M. Shedding light on chemiluminescence: the application of chemiluminescence in diagnostic andrology. J Androl. (2004) 25:455-65. doi: 10.1002/j.1939-4640.2004.tb02815.x

102. Netherton JK, Hetherington L, Ogle RA, Gavgani MM, Velkov T, Villaverde AIB, et al. Mass spectrometry reveals new insights into the production of superoxide anions and 4-hydroxynonenal adducted proteins in human sperm. Proteomics. (2020) 20:e1900205. doi: 10.1002/pmic.201900205

103. Zielonka J, Vasquez-Vivar J, Kalyanaraman B. Detection of 2hydroxyethidium in cellular systems: a unique marker product of superoxide and hydroethidine. Nat Protoc. (2008) 3:8-21. doi: 10.1038/nprot.2007.473

104. Lavi R, Shainberg A, Shneyvays V, Hochauser E, Isaac A, Zinman T, et al. Detailed analysis of reactive oxygen species induced by visible light in various cell types. Lasers Surg Med. (2010) 42:473-80. doi: 10.1002/lsm.20919

105. Kumar PG, Laloraya M, Laloraya MM. Superoxide radical level and superoxide dismutase activity changes in maturing mammalian spermatozoa. Andrologia. (1991) 23:1715. doi: 10.1111/j.1439-0272.1991.tb02528.x

106. Zhang H, Zheng RL. Promotion of human sperm capacitation by superoxide anion. Free Radic Res. (1996) 24:261-8. doi: 10.3109/10715769609088023

107. de Lamirande E, Gagnon C. Capacitation-associated production of superoxide anion by human spermatozoa. Free Radic Biol Med. (1995) 18:487-95. doi: 10.1016/0891-5849(94)00169-K

108. Sakamoto T, Imai H. Hydrogen peroxide produced by superoxide dismutase SOD-2 activates sperm in Caenorhabditis elegans. J Biol Chem. (2017) 292:14804-13. doi: 10.1074/jbc.M117.788901

109. Bize I, Santander G, Cabello P, Driscoll D, Sharpe C. Hydrogen peroxide is involved in hamster sperm capacitation in vitro. Biol Reprod. (1991) 44:398-403. doi: 10.1095/biolreprod44.3.398

110. Purdey MS, Connaughton HS, Whiting S, Schartnera EP, Monroa TM, Thompson JG, et al. Boronate probes for the detection of hydrogen peroxide release from human spermatozoa. Free Radic Biol Med. (2015) 81:6976. doi: 10.1016/j.freeradbiomed.2015.01.015

111. Herrero MB, de Lamirande E, Gagnon C. Nitric oxide is a signaling molecule in spermatozoa. Curr Pharm Des. (2003) 9:419-25. doi: 10.2174/1381612033391720

112. Herrero MB, de Lamirande E, Gagnon C. Tyrosine nitration in human spermatozoa: a physiological function of peroxynitrite, the reaction product of nitric oxide and superoxide. Mol Hum Reprod. (2001) 7:91321. doi: 10.1093/molehr/7.10.913

113. Koppers AJ, De Iuliis GN, Finnie JM, McLaughlin EA, Aitken RJ. Significance of mitochondrial reactive oxygen species in the generation of oxidative stress in spermatozoa. J Clin Endocrinol Metab. (2008) 93:3199207. doi: 10.1210/jc.2007-2616

114. Koppers AJ, Mitchell LA, Wang P, Lin M, Aitken RJ. Phosphoinositide 3-kinase signalling pathway involvement in a truncated apoptotic cascade associated with motility loss and oxidative DNA damage in human spermatozoa. Biochem J. (2011) 436:687-98. doi: 10.1042/BJ201 10114

115. Pujianto DA, Curry BJ, Aitken RJ. Prolactin exerts a prosurvival effect on human spermatozoa via mechanisms that involve the stimulation of Akt phosphorylation and suppression of caspase activation and capacitation. Endocrinology. (2010) 151:1269-79. doi: 10.1210/en.2009-0964

116. Valdivia A, Cortés L, Beitia M, Totorikaguena L, Agirregoitia N, Corcostegui B, et al. Role of angiotensin-(1-7) via MAS receptor in human sperm motility and acrosome reaction. Reproduction. (2020) 159:2419. doi: 10.1530/REP-19-0274

117. Matsuura R, Takeuchi T, Yoshida A. Preparation and incubation conditions affect the DNA integrity of ejaculated human spermatozoa. Asian J Androl. (2010) 12:753-9. doi: 10.1038/aja.2010.46

118. Krzyzosiak J, McMillan G, Molan P, Vishwanath R. Protein tyrosine phosphorylation during prolonged in vitro incubation of ejaculated bovine spermatozoa is regulated by the oxidative state of the medium. Biol Reprod. (2000) 62:1615-23. doi: 10.1095/biolreprod62.6.1615
119. Vishwanath R, Shannon P. Do sperm cells age? A review of the physiological changes in sperm during storage at ambient temperature. Reprod Fertil Dev. (1997) 9:321-31. doi: 10.1071/R96088

120. Chi HJ, Kim JH, Ryu CS, et al. Protective effect of antioxidant supplementation in sperm-preparation medium against oxidative stress in human spermatozoa. Hum Reprod. (2008) 23:10238. doi: 10.1093/humrep/den060

121. Aitken RJ, Gibb Z, Mitchell LA, Lambourne SR, Connaughton HS, De Iuliis GN. Sperm motility is lost in vitro as a consequence of mitochondrial free radical production and the generation of electrophilic aldehydes but can be significantly rescued by the presence of nucleophilic thiols. Biol Reprod. (2012) 87:110. doi: 10.1095/biolreprod.112.102020

122. Calamera JC, Fernandez PJ, Buffone MG, Acosta AA, Doncel GF. Effects of long-term in vitro incubation of human spermatozoa: functional parameters and catalase effect. Andrologia. (2001) 33:79-86. doi: 10.1046/j.1439-0272.2001.00409.x

123. Liu T, Han Y, Zhou T, et al. Mechanisms of ROS-induced mitochondriadependent apoptosis underlying liquid storage of goat spermatozoa. Aging. (2019) 11:7880-98. doi: 10.18632/aging.102295

124. Zhu Z, Kawai T, Umehara T, Hoque SAM, Zeng W, Shimada M. Negative effects of ROS generated during linear sperm motility on gene expression and ATP generation in boar sperm mitochondria. Free Radic Biol Med. (2019) 141:159-71. doi: 10.1016/j.freeradbiomed.2019.06.018

125. Swegen A, Lambourne SR, Aitken RJ, Gibb Z. Rosiglitazone improves stallion sperm motility, ATP content, and mitochondrial function. Biol Reprod. (2016) 95:107. doi: 10.1095/biolreprod.116.142687

126. Aitken RJ, Wingate JK, De Iuliis GN, Koppers AJ, McLaughlin EA. Cisunsaturated fatty acids stimulate reactive oxygen species generation and lipid peroxidation in human spermatozoa. J Clin Endocrinol Metab. (2006) 91:4154-63. doi: 10.1210/jc.2006-1309

127. Koppers AJ, Garg ML, Aitken RJ. Stimulation of mitochondrial reactive oxygen species production by unesterified, unsaturated fatty acids in defective human spermatozoa. Free Radic Biol Med. (2010) 48:1129. doi: 10.1016/j.freeradbiomed.2009.10.033

128. Samarasinghe SVAC, Krishnan K, Naidu R, Megharaj M, Miller K, Fraser $\mathrm{B}$, et al. Parabens generate reactive oxygen species in human spermatozoa. Andrology. (2018) 6:532-41. doi: 10.1111/andr.12499

129. Barbonetti A, Castellini C, Di Giammarco N, Santilli G, Francavilla S, Francavilla F. In vitro exposure of human spermatozoa to bisphenol A induces pro-oxidative/apoptotic mitochondrial dysfunction. Reprod Toxicol. (2016) 66:61-7. doi: 10.1016/j.reprotox.2016.09.014

130. Aitken RJ, Muscio L, Whiting S, Connaughton HS, Fraser BA, Nixon $\mathrm{B}$, et al. Analysis of the effects of polyphenols on human spermatozoa reveals unexpected impacts on mitochondrial membrane potential, oxidative stress and DNA integrity; implications for assisted reproductive technology. Biochem Pharmacol. (2016) 121:78-96. doi: 10.1016/j.bcp.2016.09.015

131. Fu LL, Zhang LY, An Q, Zhou F, Tiong Y, Guo Y, et al. L-carnitine protects the motion parameters and mitochondrial function of human sperm in cryopreservation. Zhonghua Nan Ke Xue. (2018) 24:1059-63.

132. Zhang X, Lu X, Li J, Xia Q, Gao J, Wu B. Mito-tempo alleviates cryodamage by regulating intracellular oxidative metabolism in spermatozoa from asthenozoospermic patients. Cryobiology. (2019) 91:18-22. doi: 10.1016/j.cryobiol.2019.11.005

133. Houston BJ, Nixon B, King BV, De Iuliis GN, Aitken RJ. The effects of radiofrequency electromagnetic radiation on sperm function. Reproduction. (2016) 152:R263-76. doi: 10.1530/REP-16-0126

134. De Iuliis GN, Newey RJ, King BV, Aitken RJ. Mobile phone radiation induces reactive oxygen species production and DNA damage in human spermatozoa in vitro. PLoS ONE. (2009) 4:e6446. doi: 10.1371/journal.pone.0006446

135. Santini SJ, Cordone V, Falone S, Mijit M, Tatone C, Amicarelli F, et al. Role of mitochondria in the oxidative stress induced by electromagnetic fields: focus on reproductive systems. Oxid Med Cell Longev. (2018) 2018:5076271. doi: 10.1155/2018/5076271

136. Agarwal A, Desai NR, Makker K, Varghese A, Mouradi R, Sabanegh E, et al. Effects of radiofrequency electromagnetic waves (RF-EMW) from cellular phones on human ejaculated semen: an in vitro pilot study. Fertil Steril. (2009) 92:1318-25. doi: 10.1016/j.fertnstert.2008.08.022 
137. Liu C, Duan W, Xu S, Chen C, He M, Zhang L, et al. Exposure to 1800 $\mathrm{MHz}$ radiofrequency electromagnetic radiation induces oxidative DNA base damage in a mouse spermatocyte-derived cell line. Toxicol Lett. (2013) 218:2-9. doi: 10.1016/j.toxlet.2013.01.003

138. Liu Q, Si T, Xu X, Liang F, Wang L, Pan S. Electromagnetic radiation at $900 \mathrm{MHz}$ induces sperm apoptosis through bcl-2, bax and caspase-3 signaling pathways in rats. Reprod Health. (2015) 12:65. doi: 10.1186/s12978-015-0062-3

139. Houston BJ, Nixon B, King BV, Aitken RJ, De Iuliis GN. Probing the origins of $1,800 \mathrm{MHz}$ radio frequency electromagnetic radiation induced damage in mouse immortalized germ cells and spermatozoa in vitro. Front Public Health. (2018) 6:270. doi: 10.3389/fpubh.2018.00270

140. Gautam R, Singh KV, Nirala J, Murmu NN, Meena R, Rajamani P. Oxidative stress-mediated alterations on sperm parameters in male wistar rats exposed to 3G mobile phone radiation. Andrologia. (2019) 51:e13201. doi: 10.1111/and.13201

141. Amaral S, Redmann K, Sanchez V, Mallidis C, RamalhoSantos J, Schlatt S. UVB irradiation as a tool to assess ROSinduced damage in human spermatozoa. Andrology. (2013) 1:707-14. doi: 10.1111/j.2047-2927.2013.00098.x

142. Moazamian R, Polhemus A, Connaughton H, Fraser B, Whiting $\mathrm{S}$, Gharagozloo $\mathrm{P}$, et al. Oxidative stress and human spermatozoa: diagnostic and functional significance of aldehydes generated as a result of lipid peroxidation. Mol Hum Reprod. (2015) 21:502-15. doi: 10.1093/molehr/gav014

143. Aitken RJ, Whiting S, De Iuliis GN, McClymont S, Mitchell LA, Baker MA. Electrophilic aldehydes generated by sperm metabolism activate mitochondrial reactive oxygen species generation and apoptosis by targeting succinate dehydrogenase. J Biol Chem. (2012) 287:3304860. doi: 10.1074/jbc.M112.366690

144. Aitken RJ, Fisher HM, Fulton N, Gomez E, Knox W, Lewis B, et al. Reactive oxygen species generation by human spermatozoa is induced by exogenous $\mathrm{NADPH}$ and inhibited by the flavoprotein inhibitors diphenylene iodonium and quinacrine. Mol Reprod Dev. (1997) 47:468-82. doi: 10.1002/(SICI)10982795(199708)47:4<468::AID-MRD14>3.0.CO;2-S

145. Miraglia E, Lussiana C, Viarisio D, Racca C, Cipriani A, Gazzano $\mathrm{E}$, et al. The pentose phosphate pathway plays an essential role in supporting human sperm capacitation. Fertil Steril. (2010) 93:243740. doi: 10.1016/j.fertnstert.2009.09.005

146. Richer SC, Ford WC. A critical investigation of NADPH oxidase activity in human spermatozoa. Mol Hum Reprod. (2001) 7:23744. doi: 10.1093/molehr/7.3.237

147. Ford WC. Regulation of sperm function by reactive oxygen species. Hum Reprod Update. (2004) 10:387-99. doi: 10.1093/humupd/dmh034

148. Bánfi B, Molnár G, Maturana A, Steger K, Hegedûs B, Demaurex $\mathrm{N}$, et al. $\mathrm{A} \mathrm{Ca}(2+)$-activated $\mathrm{NADPH}$ oxidase in testis, spleen, and lymph nodes. J Biol Chem. (2001) 276:37594-601. doi: 10.1074/jbc.M1030 34200

149. Musset B, Clark RA, DeCoursey TE, Petheo GL, Geiszt M, Chen Y, et al. NOX5 in human spermatozoa: expression, function, and regulation. J Biol Chem. (2012) 287:9376-88. doi: 10.1074/jbc.M111.314955

150. du Plessis SS, McAllister DA, Luu A, Savia J, Agarwal A, Lampiao F. Effects of $\mathrm{H}(2) \mathrm{O}(2)$ exposure on human sperm motility parameters, reactive oxygen species levels and nitric oxide levels. Andrologia. (2010) 42:20610. doi: 10.1111/j.1439-0272.2009.00980.x

151. Mahfouz RZ, du Plessis SS, Aziz N, Sharma R, Sabanegh E, Agarwal A. Sperm viability, apoptosis, and intracellular reactive oxygen species levels in human spermatozoa before and after induction of oxidative stress. Fertil Steril. (2010) 93:814-21. doi: 10.1016/j.fertnstert.200 8.10 .068

152. de Lamirande E, Lamothe G. Reactive oxygen-induced reactive oxygen formation during human sperm capacitation. Free Radic Biol Med. (2009) 46:502-10. doi: 10.1016/j.freeradbiomed.2008.11.004

153. Rivlin J, Mendel J, Rubinstein S, Etkovitz N, Breitbart H. Role of hydrogen peroxide in sperm capacitation and acrosome reaction. Biol Reprod. (2004) 70:518-22. doi: 10.1095/biolreprod.103.020487

154. Aitken RJ, Harkiss D, Knox W, Paterson M, Irvine DS. A novel signal transduction cascade in capacitating human spermatozoa characterised by a redox-regulated, cAMP-mediated induction of tyrosine phosphorylation. $J$ Cell Sci. (1998) 111:645-56.

155. Lewis B, Aitken RJ. A redox-regulated tyrosine phosphorylation cascade in rat spermatozoa. J Androl. (2001) 22:611-22.

156. Baker MA, Hetherington L, Curry B, Aitken RJ. Phosphorylation and consequent stimulation of the tyrosine kinase c-Abl by PKA in mouse spermatozoa; its implications during capacitation. Dev Biol. (2009) 333:5766. doi: 10.1016/j.ydbio.2009.06.022

157. Vatannejad A, Tavilani H, Sadeghi MR, Karimi M, Lakpour N, Amanpour $\mathrm{S}$, et al. Evaluation of the NOX5 protein expression and oxidative stress in sperm from asthenozoospermic men compared to normozoospermic men. J Endocrinol Invest. (2019) 42:1181-9. doi: 10.1007/s40618-019-01035-4

158. Ghani E, Keshtgar S, Habibagahi M, Ghannadi A, Kazeroni M. Expression of NOX5 in human teratozoospermia compared to normozoospermia. Andrologia. (2013) 45:351-6. doi: 10.1111/and.12023

159. Ghanbari H, Keshtgar S, Zare HR, Gharesi-Fard B. Inhibition of CatSper and Hv1 channels and NOX5 enzyme affect progesterone-induced increase of intracellular calcium concentration and ROS generation in human sperm. Iran J Med Sci. (2019) 44:127-34.

160. Kirichok Y, Navarro B, Clapham DE. Whole-cell patch-clamp measurements of spermatozoa reveal an alkaline-activated Ca2+ channel. Nature. (2006) 439:737-40. doi: 10.1038/nature04417

161. Gomez E, Buckingham DW, Brindle J, Lanzafame F, Irvine DS, Aitken RJ. Development of an image analysis system to monitor the retention of residual cytoplasm by human spermatozoa: correlation with biochemical markers of the cytoplasmic space, oxidative stress, and sperm function. $J$ Androl. (1996) 17:276-87.

162. Ecroyd HW, Jones RC, Aitken RJ. Endogenous redox activity in mouse spermatozoa and its role in regulating the tyrosine phosphorylation events associated with sperm capacitation. Biol Reprod. (2003) 69:34754. doi: 10.1095/biolreprod.102.012716

163. Fischer KA, Van Leyen K, Lovercamp KW, Manandhar G, Sutovsky M, Feng D, et al. 15-Lipoxygenase is a component of the mammalian sperm cytoplasmic droplet. Reproduction. (2005) 130:213-22. doi: 10.1530/rep.1.00646

164. Roy P, Roy SK, Mitra A, Kulkarni AP. Superoxide generation by lipoxygenase in the presence of NADH and NADPH. Biochim Biophys Acta. (1994) 1214:171-9. doi: 10.1016/0005-2760(94)90041-8

165. Bromfield EG, Mihalas BP, Dun MD, Aitken RJ, McLaughlin EA, Walters JLH, et al. Inhibition of arachidonate 15-lipoxygenase prevents 4hydroxynonenal-induced protein damage in male germ cells. Biol Reprod. (2017) 96:598-609. doi: 10.1093/biolre/iox005

166. Walters JLH, De Iuliis GN, Dun MD, Aitken RJ, McLaughlin EA, Nixon B, et al. Pharmacological inhibition of arachidonate 15-lipoxygenase protects human spermatozoa against oxidative stress. Biol Reprod. (2018) 98:78494. doi: 10.1093/biolre/ioy058

167. Aitken RJ, Harkiss D, Buckingham DW. Analysis of lipid peroxidation mechanisms in human spermatozoa. Mol Reprod Dev. (1993) 35:30215. doi: 10.1002/mrd.1080350313

168. Tosic J, Walton A. Formation of hydrogen peroxide by spermatozoa and its inhibitory effect of respiration. Nature. (1946) 158:485. doi: 10.1038/158485a0

169. Tosic J, Walton A. Metabolism of spermatozoa. The formation and elimination of hydrogen peroxide by spermatozoa and effects on motility and survival. Biochem J. (1950) 47:199-212. doi: 10.1042/bj0470199

170. Aitken JB, Naumovski N, Curry B, Grupen CG, Gibb Z, Aitken RJ. Characterization of an L-amino acid oxidase in equine spermatozoa. Biol Reprod. (2015) 92:125. doi: 10.1095/biolreprod.114.126052

171. Upreti GC, Jensen K, Munday R, Duganzich DM, Vishwanath R, Smith JF. Studies on aromatic amino acid oxidase activity in ram spermatozoa: role of pyruvate as an antioxidant. Anim Reprod Sci. (1998) 51:27587. doi: 10.1016/S0378-4320(98)00082-7

172. Houston B, Curry B, Aitken RJ. Human spermatozoa possess an IL4I1 1amino acid oxidase with a potential role in sperm function. Reproduction. (2015) 149:587-96. doi: 10.1530/REP-14-0621

173. Fernandez MC, Yu A, Moawad AR, O’Flaherty C. Peroxiredoxin 6 regulates the phosphoinositide 3-kinase/AKT pathway to maintain human sperm viability. Mol Hum Reprod. (2019) 25:787-96. doi: 10.1093/molehr/gaz060 
174. Williams AC, Ford WC. Functional significance of the pentose phosphate pathway and glutathione reductase in the antioxidant defenses of human sperm. Biol Reprod. (2004) 71:1309-16. doi: 10.1095/biolreprod.104.028407

175. Jeulin C, Soufir JC, Weber P, Laval-Martin D, Calvayrac R. Catalase activity in human spermatozoa and seminal plasma. Gamete Res. (1989) 24:18596. doi: 10.1002/mrd.1120240206

176. Aitken RJ, Roman SD. Antioxidant systems and oxidative stress in the testes. Oxid Med Cell Longev. (2008) 1:15-24. doi: 10.4161/oxim.1.1.6843

177. Koziorowska-Gilun M, Koziorowski M, Fraser L, Strzezek J. Antioxidant defence system of boar cauda epididymidal spermatozoa and reproductive tract fluids. Reprod Domest Anim. (2011) 46:527-33. doi: 10.1111/j.1439-0531.2010.01701.x

178. Rhemrev JP, van Overveld FW, Haenen GR, Teerlink T, Bast A, Vermeiden JP. Quantification of the nonenzymatic fast and slow TRAP in a postaddition assay in human seminal plasma and the antioxidant contributions of various seminal compounds. J Androl. (2000) 21:913-20.

179. Faulkner S, Elia G, Mullen MP, O’Boyle P, Dunn MJ, Morris D. A comparison of the bovine uterine and plasma proteome using iTRAQ proteomics. Proteomics. (2012) 12:2014-23. doi: 10.1002/pmic.201100609

180. Benedetti S, Tagliamonte MC, Catalani S, Primiterra M, Canestrari F, De Stefani S, et al. Differences in blood and semen oxidative status in fertile and infertile men, and their relationship with sperm quality. Reprod Biomed Online. (2012) 25:300-6. doi: 10.1016/j.rbmo.2012.05.011

181. Gupta S, Finelli R, Agarwal A, Henkel R. Total antioxidant capacityrelevance, methods and clinical implications Andrologia. (2020) 12:e13624. doi: 10.1111/and.13624

182. Nassan FL, Chavarro JE, Tanrikut C. Diet and men's fertility: does diet affect sperm quality? Fertil Steril. (2018) 110:5707. doi: 10.1016/j.fertnstert.2018.05.025

183. Pasqualotto FF, Sundaram A, Sharma RK, Borges E, Jr, Pasqualotto EB, Agarwal A. Semen quality and oxidative stress scores in fertile and infertile patients with varicocele. Fertil Steril. (2008) 89:6027. doi: 10.1016/j.fertnstert.2007.03.057

184. Mostafa T, Tawadrous G, Roaia MM, Amer MK, Kader RA, Aziz A. Effect of smoking on seminal plasma ascorbic acid in infertile and fertile males. Andrologia. (2006) 38:221-4. doi: 10.1111/j.1439-0272.2006.00744.x

185. Ferigolo PC, Ribeiro de Andrade MB, Camargo M, Carvalho VM, Cardozo KHM, Bertolla RP, et al. Sperm functional aspects and enriched proteomic pathways of seminal plasma of adult men with obesity. Andrology. (2019) 7:341-9. doi: 10.1111/andr.12606

186. Zhang MH, Zhai LP, Fang ZY, Li AN, Xiao W, Qiu Y. Effect of scrotal heating on sperm quality, seminal biochemical substances, and reproductive hormones in human fertile men. J Cell Biochem. (2018) 119:1022838. doi: $10.1002 / \mathrm{jcb} .27365$

187. Samova S, Doctor H, Verma R. In vivo analysis of bisphenol A induced dosedependent adverse effects in cauda epididymis of mice. Interdiscip Toxicol. (2018) 11:209-16. doi: 10.2478/intox-2018-0019

188. Storey BT. Biochemistry of the induction and prevention of lipoperoxidative damage in human spermatozoa. Mol Hum Reprod. (1997) 3:20313. doi: $10.1093 / \mathrm{molehr} / 3.3 .203$

189. Gharagozloo P, Aitken RJ. The role of sperm oxidative stress in male infertility and the significance of oral antioxidant therapy. Hum Reprod. (2011) 26:1628-40. doi: 10.1093/humrep/der132

190. Gharagozloo P, Gutiérrez-Adán A, Champroux A, Noblanc A, Kocer A, Calle A, et al. A novel antioxidant formulation designed to treat male infertility associated with oxidative stress: promising preclinical evidence from animal models. Hum Reprod. (2016) 31:252-62. doi: 10.1093/humrep/dev302

191. Suleiman SA, Ali ME, Zaki ZM, el-Malik EM, Nasr MA. Lipid peroxidation and human sperm motility: protective role of vitamin E. J Androl. (1996) 17:530-7.

192. Dhawan V, Kumar M, Deka D, Malhotra N, Dadhwal V, Singh $\mathrm{N}$, et al. Meditation \& yoga: impact on oxidative DNA damage and dysregulated sperm transcripts in male partners of couples with recurrent pregnancy loss. Indian J Med Res. (2018) 148(Suppl):S1349. doi: 10.4103/ijmr.IJMR_1988_17

193. Bisht S, Banu S, Srivastava S, Pathak RU, Kumar R, Dada R, et al. Sperm methylome alterations following yoga-based lifestyle intervention in patients of primary male infertility: a pilot study. Andrologia. (2020) 52:e13551. doi: 10.1111/and.13551

194. Sakkas D, Urner F, Bizzaro D, Manicardi G, Bianchi PG, Shoukir Y, et al. Sperm nuclear DNA damage and altered chromatin structure: effect on fertilization and embryo development. Hum Reprod. (1998) 13(Suppl 4):11-9. doi: 10.1093/humrep/13.suppl_4.11

195. Casanovas A, Ribas-Maynou J, Lara-Cerrillo S, Jimenez-Macedo R, Hortal $\mathrm{O}$, Benet J, et al. Double-stranded sperm DNA damage is a cause of delay in embryo development and can impair implantation rates. Fertil Steril. (2019) 111:699-707.e1. doi: 10.1016/j.fertnstert.2018.11.035

196. Aitken RJ, Gordon E, Harkiss D, Twigg J, Milne P, Jennings Z, et al. Relative impact of oxidative stress on the functional competence and genomic integrity of human spermatozoa. Biol Reprod. (1998) 59:103746. doi: 10.1095/biolreprod59.5.1037

197. Lord T, Aitken RJ. Fertilization stimulates 8-hydroxy-2'-deoxyguanosine repair and antioxidant activity to prevent mutagenesis in the embryo. Dev Biol. (2015) 406:1-13. doi: 10.1016/j.ydbio.201 5.07.024

198. Vorilhon S, Brugnon F, Kocer A, Dollet S, Bourgne C, Berger M, et al. Accuracy of human sperm DNA oxidation quantification and threshold determination using an $8-\mathrm{OHdG}$ immuno-detection assay. Hum Reprod. (2018) 33:553-62. doi: 10.1093/humrep/dey038

199. Aitken RJ, De Iuliis GN, Finnie JM, Hedges A, McLachlan RI. Analysis of the relationships between oxidative stress, DNA damage and sperm vitality in a patient population: development of diagnostic criteria. Hum Reprod. (2010) 25:2415-26. doi: 10.1093/humrep/deq214

200. Ohno M, Sakumi K, Fukumura R, Furuichi M, Iwasaki Y, Hokama M, et al. 8-oxoguanine causes spontaneous de novo germline mutations in mice. Sci Rep. (2014) 4:4689. doi: 10.1038/srep04689

201. Horta F, Catt S, Ramachandran P, Vollenhoven B, Temple-Smith P. Female ageing affects the DNA repair capacity of oocytes in IVF using a controlled model of sperm DNA damage in mice. Hum Reprod. (2020) 35:52944. doi: 10.1093/humrep/dez308

202. Sedha S, Kumar S, Shukla S. Role of oxidative stress in male reproductive dysfunctions with reference to phthalate compounds. Urol J. (2015) 12:230416.

203. Aitken RJ, Drevet JR. The importance of oxidative stress in determining the functionality of mammalian spermatozoa: a two-edged sword. Antioxidants. (2020) 9:111. doi: 10.3390/antiox9020111

204. Taylor JD, Baumgartner A, Schmid TE, Brinkworth MH. Responses to genotoxicity in mouse testicular germ cells and epididymal spermatozoa are affected by increased age. Toxicol Lett. (2019) 310:1-6. doi: 10.1016/j.toxlet.2019.04.013

205. Lu Y, Lin M, Aitken RJ. Exposure of spermatozoa to dibutyl phthalate induces abnormal embryonic development in a marine invertebrate Galeolaria caespitosa (Polychaeta: Serpulidae). Aquat Toxicol. (2017) 191:189-200. doi: 10.1016/j.aquatox.2017.08.008

206. Darmishonnejad Z, Zarei-Kheirabadi F, Tavalaee M, Zarei-Kheirabadi M, Zohrabi D, Nasr-Esfahani MH. Relationship between sperm telomere length and sperm quality in infertile men. Andrologia. (2020) 52:e13546. doi: 10.1111/and.13546

207. Xavier MJ, Nixon B, Roman SD, Scott RJ, Drevet JR, Aitken RJ. Paternal impacts on development: identification of genomic regions vulnerable to oxidative DNA damage in human spermatozoa. Hum Reprod. (2019) 34:1876-90. doi: 10.1093/humrep/dez153

208. Zhang H, Wang R, Yu Y, Zhu H, Li L, Yang $\mathrm{X}$, et al. Nonrobertsonian translocations involving chromosomes 13, 14, or 15 in male infertility: 28 cases and a review of the literature. Medicine. (2019) 98:e14730. doi: 10.1097/MD.000000000001 4730

209. Wu H, Sun L, Wen Y, Liu Y, Yu J, Mao F, et al. Major spliceosome defects cause male infertility and are associated with nonobstructive azoospermia in humans. Proc Natl Acad Sci USA. (2016) 113:41349. doi: $10.1073 /$ pnas. 1513682113

210. Jaiswal D, Singh V, Dwivedi US, Trivedi S, Singh K. Chromosome microarray analysis: a case report of infertile brothers with CATSPER gene deletion. Gene. (2014) 542:263-5. doi: 10.1016/j.gene.2014.03.055 
211. Sun M, Wang R, Zhang H, Jiang Y, He J, Li S, et al. Molecular cytogenetic characterization of small supernumerary marker 15 in infertile male: a case report. Exp Ther Med. (2020) 19:2927-32. doi: 10.3892/etm.2020.8542

212. Zhang Y, Malekpour M, Al-Madani N, Kahrizi ZK, Zanganeh M, Mohseni M, et al. Sensorineural deafness and male infertility: a contiguous gene deletion syndrome. J Med Genet. (2007) 44:233-40. doi: 10.1136/jmg.2006.045765

213. Aitken RJ, De Iuliis GN, Nixon B. The sins of our forefathers: paternal impacts on de novo mutation rate and development. Ann Rev Genet. (2020). doi: 10.1146/annurev-genet-112618-043617

214. Kissin DM, Zhang Y, Boulet SL, Fountain C, Bearman P, Schieve L, et al. Association of assisted reproductive technology (ART) treatment and parental infertility diagnosis with autism in ART-conceived children. Hum Reprod. (2015) 30:454-65. doi: 10.1093/humrep/deu338

215. Hattori H, Hiura H, Kitamura A, Miyauchi N, Kobayashi N, Takahashi S, et al. Association of four imprinting disorders and ART. Clin Epigenetics. (2019) 11:21. doi: 10.1186/s13148-019-0 623-3

216. Amos-Landgraf JM, Ji Y, Gottlieb W, Wandstrat AE, Cassidy SB, Driscoll DJ, et al. Chromosome breakage in the prader-willi and angelman syndromes involves recombination between large, transcribed repeats at proximal and distal breakpoints. Am J Hum Genet. (1999) 65:370-86. doi: 10.1086/302510

217. Fraga CG, Motchnik PA, Shigenaga MK, Helbock HJ, Jacob RA, Ames BN. Ascorbic acid protects against endogenous oxidative DNA damage in human sperm. Proc Natl Acad Sci USA. (1991) 88:110036. doi: 10.1073/pnas.88.24.11003

218. Ji G, Yan L, Liu W, Qu J, Gu A. OGG1 Ser326Cys polymorphism interacts with cigarette smoking to increase oxidative DNA damage in human sperm and the risk of male infertility. Toxicol Lett. (2013) 218:1449. doi: 10.1016/j.toxlet.2013.01.017

219. Lee KM, Ward MH, Han S, Ahn HS, Kang HJ, Choi HS, et al. Paternal smoking, genetic polymorphisms in CYP1A1 and childhood leukemia risk. Leuk Res. (2009) 33:250-8. doi: 10.1016/j.leukres.2008.06.031

220. Heerema NA, Sather HN, Sensel MG, La MK, Hutchinson RJ, Nachman JB, et al. Abnormalities of chromosome bands 15q13-15 in childhood acute lymphoblastic leukemia. Cancer. (2002) 94:1102-10. doi: 10.1002/cncr.10325
221. Beal MA, Yauk CL, Marchetti F. From sperm to offspring: assessing the heritable genetic consequences of paternal smoking and potential public health impacts. Mutat Res. (2017) 773:2650. doi: 10.1016/j.mrrev.2017.04.001

222. Kinoshita T, Mikami M, Ayabe T, Matsubara K, Ono H, Ohki K, et al. Frequency of common copy-number variations at $15 \mathrm{q} 11.2 \mathrm{q} 13$ in sperm of healthy men. Cytogenet Genome Res. (2019) 159:6673. doi: $10.1159 / 000503267$

223. Butler MG. Clinical and genetic aspects of the $15 \mathrm{q} 11.2$ BP1BP2 microdeletion disorder. J Intellect Disabil Res. (2017) 61:568-79. doi: 10.1111/jir.12382

224. Ferlin A, Foresta C. Infertility: practical clinical issues for routine investigation of the male partner. J Clin Med. (2020) 9:1644. doi: $10.3390 / \mathrm{jcm} 9061644$

225. Khosravizadeh Z, Hassanzadeh G, Tavakkoly Bazzaz J, Alizadeh F, Totonchi M, Salehi E, et al. The effect of cryopreservation on DNA methylation patterns of the chromosome 15q11-q13 region in human spermatozoa. Cell Tissue Bank. (2020) 21:433-45. doi: 10.1007/s10561-02009828-1

226. Houston BJ, Nixon B, Martin JH, De Iuliis GN, Trigg NA, Bromfield EG, et al. Heat exposure induces oxidative stress and DNA damage in the male germ line. Biol Reprod. (2018) 98:593-606. doi: 10.1093/biolre/ ioy009

Conflict of Interest: The authors declare that the research was conducted in the absence of any commercial or financial relationships that could be construed as a potential conflict of interest.

Copyright (c) 2020 Aitken and Baker. This is an open-access article distributed under the terms of the Creative Commons Attribution License (CC BY). The use, distribution or reproduction in other forums is permitted, provided the original author(s) and the copyright owner(s) are credited and that the original publication in this journal is cited, in accordance with accepted academic practice. No use, distribution or reproduction is permitted which does not comply with these terms. 